\title{
NETL-EERC ENVIRONMENTAL MANAGEMENT COOPERATIVE AGREEMENT
}

1994-2001 Final Report

Prepared for:

AAD Document Control

U.S. Department of Energy

National Energy Technology Laboratory

626 Cochrans Mill Road

PO Box 10940, MS 921-143

Pittsburgh, PA 15236-0940

Cooperative Agreement No. DE-FC21-94MC31388

Performance Monitor: Dr. Edgar B. Klunder
Prepared by:

Christina B. Behr-Andres Daniel J. Daly

Energy \& Environmental Research Center

University of North Dakota

PO Box 9018

Grand Forks, ND 58202-9018 


\section{DOE DISCLAIMER}

This report was prepared as an account of work sponsored by an agency of the United States Government. Neither the United States Government, nor any agency thereof, nor any of their employees makes any warranty, express or implied, or assumes any legal liability or responsibility for the accuracy, completeness, or usefulness of any information, apparatus, product, or process disclosed or represents that its use would not infringe privately owned rights. Reference herein to any specific commercial product, process, or service by trade name, trademark, manufacturer, or otherwise does not necessarily constitute or imply its endorsement, recommendation, or favoring by the United States Government or any agency thereof. The views and opinions of authors expressed herein do not necessarily state or reflect those of the United States Government or any agency thereof.

This report is available to the public from the National Technical Information Service, U.S. Department of Commerce, 5285 Port Royal Road, Springfield, VA 22161; phone orders accepted at (703) 487-4650.

\section{ACKNOWLEDGMENT}

This report was prepared with the support of the U.S. Department of Energy (DOE) National Energy Technology Laboratory Cooperative Agreement No. DE-FC21-94MC31388. However, any opinions, findings, conclusions, or recommendations expressed herein are those of the authors(s) and do not necessarily reflect the views of DOE.

\section{EERC DISCLAIMER}

LEGAL NOTICE This research report was prepared by the Energy \& Environmental Research Center (EERC), an agency of the University of North Dakota, as an account of work sponsored by DOE. Because of the research nature of the work performed, neither the EERC nor any of its employees makes any warranty, express or implied, or assumes any legal liability or responsibility for the accuracy, completeness, or usefulness of any information, apparatus, product, or process disclosed, or represents that its use would not infringe privately owned rights. Reference herein to any specific commercial product, process, or service by trade name, trademark, manufacturer, or otherwise does not necessarily constitute or imply its endorsement or recommendation by the EERC. 


\section{TABLE OF CONTENTS}

LIST OF TABLES $\ldots \ldots \ldots \ldots \ldots \ldots \ldots \ldots \ldots \ldots \ldots \ldots \ldots \ldots \ldots \ldots \ldots$

EMCA ACCOMPLISHMENTS $\ldots \ldots \ldots \ldots \ldots \ldots \ldots \ldots \ldots \ldots \ldots \ldots \ldots \ldots$

Technology Commercialization Accomplishments $\ldots \ldots \ldots \ldots \ldots \ldots \ldots \ldots \ldots$

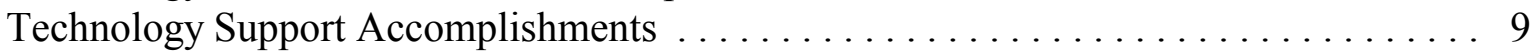

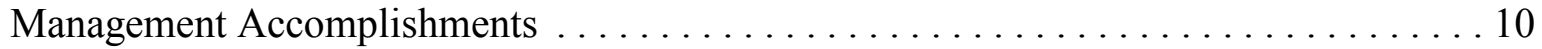

TASK SUMMARIES FOR THE NETL-EERC

EM COOPERATIVE AGREEMENT .................... Appendix A

\section{LIST OF TABLES}

1 Summary of Tasks for the NETL-EERC EM Cooperative Agreement . . . . . . . . . . 2

2 Summary of Achievements of the NETL-EERC EM Cooperative Agreement . . . . . . . . 3

3 Selected EM Technology Success Stories from the EERC $\ldots \ldots \ldots \ldots \ldots \ldots \ldots \ldots \ldots$ 


\section{NETL-EERC ENVIRONMENTAL MANAGEMENT COOPERATIVE AGREEMENT}

\section{EMCA ACCOMPLISHMENTS}

This final report summarizes the accomplishments of the 6-year Environmental Management Cooperative Agreement (EMCA) between the Energy \& Environmental Research Center (EERC), a nonprofit, contract-supported unit of the University of North Dakota, and the U.S. Department of Energy (DOE) National Energy Technology Laboratory (NETL). The first portion of the report summarizes EMCA's structure, activities, and accomplishments. The appendix contains profiles of the individual EMCA tasks. Detailed descriptions and results of the tasks can be found separately in published Final Topical Reports.

EMCA (DOE Contract No. DE-FC21-94MC31388) was in place from the fall of 1994 to the summer of 2001. Under EMCA, approximately \$5.4 million was applied in three program areas to expedite the commercialization of 15 innovative technologies for application in DOE's EM Program (\$3.8 million, or 69\% of funds), provide technical support to the Deactivation and Decommissioning Focus Area (DDFA; $\$ 1.04$ million, or 19\% of funds), and provide for the coordination of the EMCA activities ( $\$ 0.62$ million, or $11 \%$ of funds).

The following sections profile the overall accomplishments of the EMCA program followed by a summary of the accomplishments under each of the EMCA areas:

commercialization, DDFA technical support, and management. Table 1 provides an overview of EMCA, including program areas, program activities, the duration and funding of each activity, and the associated industry partner, if appropriate.

\section{Technology Commercialization Accomplishments}

With respect to innovative technology commercialization, the EERC supported NETL's EM activities by arranging and implementing partnerships to accelerate the commercial application of improved technologies and systems addressing critical needs within DOE's designated Focus Areas of TRU (transuranic) and Mixed Waste, Tanks Remediation, Subsurface Contaminants, and Deactivation and Decommissioning (D\&D).

Technology tasks were typically initiated and continued only where there was an interested industrial commercialization partner, the technology was in the Advanced Development stage, and the technology was clearly relevant to EM needs as identified by the associated Site Technical Coordination Group. Particular emphasis was given to providing technical support to NETL EM industry partners.

Table 2 summarizes the strategic accomplishments for commercialization activities. Detailed summaries can be found in the appendix. Table 3 summarizes select "success stories." 
TABLE 1

Summary of Tasks for the NETL-EERC EM Cooperative Agreement

\begin{tabular}{|c|c|c|c|}
\hline Task Name & Industry Partner & $\begin{array}{l}\text { Period of } \\
\text { Performance }\end{array}$ & $\begin{array}{c}\text { Total } \\
\text { Cost, } \$\end{array}$ \\
\hline $\begin{array}{l}\text { Provide Information Required for Compliance with } \\
\text { the National Environmental Policy Act (NEPA) }\end{array}$ & - & 9/94-9/95 & $5 \mathrm{~K}$ \\
\hline Extraction and Analysis of Pollutant Organics & Suprex & 9/94-1/97 & $383 \mathrm{~K}$ \\
\hline Pyrolysis of Plastic Waste & - & 9/94-12/97 & $588 \mathrm{~K}$ \\
\hline $\begin{array}{l}\text { Stabilization of Vitrified Waste by Enhanced } \\
\text { Crystallization and Development of a Protocol to } \\
\text { Predict Long-Term Stability }\end{array}$ & - & 9/94-9/95 & $80 \mathrm{~K}$ \\
\hline Integration, Management, and Reporting & - & 9/94-6/01 & $614 \mathrm{~K}$ \\
\hline Centrifugal Membrane Filtration & SpinTek and 3M & 9/94-12/98 & $557 \mathrm{~K}$ \\
\hline $\begin{array}{l}\text { Systems Analysis of Environmental Management } \\
\text { Technologies }\end{array}$ & - & $4 / 96-12 / 97$ & $507 \mathrm{~K}$ \\
\hline Laser Cleaning of Contaminated Painted Surfaces & F2 Associates & 9/95-12/98 & $250 \mathrm{~K}$ \\
\hline Cone Penetrometer for Subsurface Metal Detection & $\begin{array}{l}\text { Science \& Engineering } \\
\text { Associates, Inc. }\end{array}$ & $12 / 96-12 / 98$ & $580 \mathrm{~K}$ \\
\hline Bubbleless Gas-Transfer Technology & $\begin{array}{l}\text { Baumgartner Environics, } \\
\text { Inc. }\end{array}$ & $12 / 96-12 / 98$ & $137 \mathrm{~K}$ \\
\hline $\begin{array}{l}\text { Remediation of Organically Contaminated Soils } \\
\text { Using Hot/Liquid (Subcritical) Water }\end{array}$ & - & $12 / 96-6 / 01$ & $504 \mathrm{~K}$ \\
\hline $\begin{array}{l}\text { Preparation of Sampling/Analysis and Availability } \\
\text { Assurance Plans and Thermodynamic Modeling of } \\
\text { Volatile Hazardous Metal Behavior in the Vortec } \\
\text { Vitrification System }\end{array}$ & Vortec Corporation & $12 / 96-12 / 97$ & $39 \mathrm{~K}$ \\
\hline $\begin{array}{l}\text { Use of Acoustic Energy and Humic Acids to } \\
\text { Mobilize DNAPLs in the Subsurface }\end{array}$ & Weiss Associates & $6 / 97-12 / 98$ & $122 \mathrm{~K}$ \\
\hline $\begin{array}{l}\text { Carbon Sorbent Optimization and Evaluation for } \\
\text { High Levels of Mercury Contamination }\end{array}$ & $\begin{array}{l}\text { Mercury Recovery } \\
\text { Services }\end{array}$ & $12 / 97-12 / 98$ & $169 \mathrm{~K}$ \\
\hline $\begin{array}{l}\text { Sampling, Analysis, and Vitrification Study for the } \\
\text { ThermoChem Steam Reformer Treatment Technology }\end{array}$ & ThermoChem, Inc. & $12 / 97-12 / 98$ & $73 \mathrm{~K}$ \\
\hline $\begin{array}{l}\text { Prevention of Chloride Corrosion in High- } \\
\text { Temperature Waste Treatment Systems }\end{array}$ & GTS Duratek & $12 / 97-10 / 00$ & $200 \mathrm{~K}$ \\
\hline $\begin{array}{l}\text { Development of Systems Engineering Applications } \\
\text { for Deactivation and Decommissioning Activities }\end{array}$ & NETL DDFA & $6 / 98-12 / 99$ & $450 \mathrm{~K}$ \\
\hline $\begin{array}{l}\text { Development of an in Situ Instrument for Measuring } \\
\text { Mercury in a Gas Stream }\end{array}$ & $\begin{array}{c}\text { Sensor Research \& } \\
\text { Development Corporation }\end{array}$ & $1 / 99-6 / 01$ & $80 \mathrm{~K}$ \\
\hline Processing Contaminated Plant Residues & Phytokinetics, Inc. & 10/99-12/99 & $50 \mathrm{~K}$ \\
\hline $\begin{array}{l}\text { Integrated Chemical Reaction Kinetics in } \\
\text { Contaminant Transport Model }\end{array}$ & DIAMO Ltd. & 10/99-12/99 & $25 \mathrm{~K}$ \\
\hline
\end{tabular}




\section{TABLE 2}

\section{Summary of Achievements of the NETL-EERC EM Cooperative Agreement}

\begin{tabular}{|c|c|c|c|c|c|c|}
\hline \multirow[b]{2}{*}{ EM Technology } & \multirow[b]{2}{*}{$\begin{array}{l}\text { Commercial } \\
\text { Partner }\end{array}$} & \multirow{2}{*}{$\begin{array}{l}\text { Technology } \\
\text { Design } \\
\text { Modification } \\
\text { and Testing } \\
\text { (lab-to-full- } \\
\text { scale field) }\end{array}$} & \multirow{2}{*}{$\begin{array}{l}\text { Process Steam } \\
\text { and By-Product } \\
\text { Sampling, } \\
\text { Analysis, } \\
\text { Characterization, } \\
\text { or Modeling }\end{array}$} & \multirow[b]{2}{*}{$\begin{array}{l}\text { Integration } \\
\text { Assessment }\end{array}$} & \multicolumn{2}{|c|}{$\begin{array}{c}\text { Technology } \\
\text { Demonstration(s) }\end{array}$} \\
\hline & & & & & Planned & $\begin{array}{l}\text { Active or } \\
\text { Completed }\end{array}$ \\
\hline $\begin{array}{l}\text { Automated Laser-Based Units for } \\
\text { Removing Contaminated Paints and } \\
\text { Surface Coatings }\end{array}$ & F2 Associates & & & & & \\
\hline $\begin{array}{l}\text { Centrifugal Membrane Filtration for } \\
\text { Aqueous Stream Treatment }\end{array}$ & $\begin{array}{c}\text { SpinTek } \\
\text { Membrane } \\
\text { Systems, Inc. }\end{array}$ & & & & & \\
\hline $\begin{array}{l}\text { Fiber-Optic Cone Penetrometer System } \\
\text { for Subsurface Metal Detection }\end{array}$ & $\begin{array}{l}\text { Science \& } \\
\text { Engineering } \\
\text { Associates }\end{array}$ & & & & & \\
\hline $\begin{array}{l}\text { Bubbleless Gas-Transfer Technology } \\
\text { for In Situ Bioremediation of } \\
\text { Chlorinated Hydrocarbons }\end{array}$ & $\begin{array}{l}\text { Baumgartner } \\
\text { Environics } \\
\text { Incorporated }\end{array}$ & & & & & \\
\hline $\begin{array}{l}\text { Subcritical Water Technology for } \\
\text { Treatment of Hydrocarbon- } \\
\text { Contaminated Soil }\end{array}$ & Pending & & & & & \\
\hline Waste Vitrification Facility & $\begin{array}{l}\text { Vortec } \\
\text { Corporation }\end{array}$ & & & & & \\
\hline $\begin{array}{l}\text { Field SFE and Field SFE-FT-IR } \\
\text { Extraction and Analysis of } \\
\text { Organic Pollutants }\end{array}$ & $\begin{array}{c}\text { Suprex } \\
\text { Corporation }\end{array}$ & & & & & \\
\hline $\begin{array}{l}\text { Acoustic Enhancement of } \\
\text { Groundwater Remediation }\end{array}$ & $\begin{array}{c}\text { Weiss } \\
\text { Associates }\end{array}$ & & & & & \\
\hline Mercury Removal from Solid Materials & MRS & & & & & \\
\hline $\begin{array}{l}\text { Steam Reforming of } \\
\text { Hazardous Materials }\end{array}$ & ThermoChem & & & & & \\
\hline $\begin{array}{l}\text { Chlorine Removal from } \\
\text { High-Temperature Systems }\end{array}$ & GTS Duratek & & & & & \\
\hline $\begin{array}{l}\text { Development of an In Situ Instrument } \\
\text { for Measuring Mercury in a Gas Stream }\end{array}$ & $\begin{array}{c}\text { Sensor } \\
\text { Research \& } \\
\text { Development } \\
\text { Corporation }\end{array}$ & & & & & \\
\hline Processing Contaminated Plant Residues & Phytokinetics & & & & & \\
\hline $\begin{array}{l}\text { Integrated Chemical Reaction Kinetics } \\
\text { in Contaminated Transport Model }\end{array}$ & DIAMO & & & & & \\
\hline
\end{tabular}

\footnotetext{
it Deployments.
} 


\section{TABLE 3}

Selected EM Technology Success Stories from the EERC

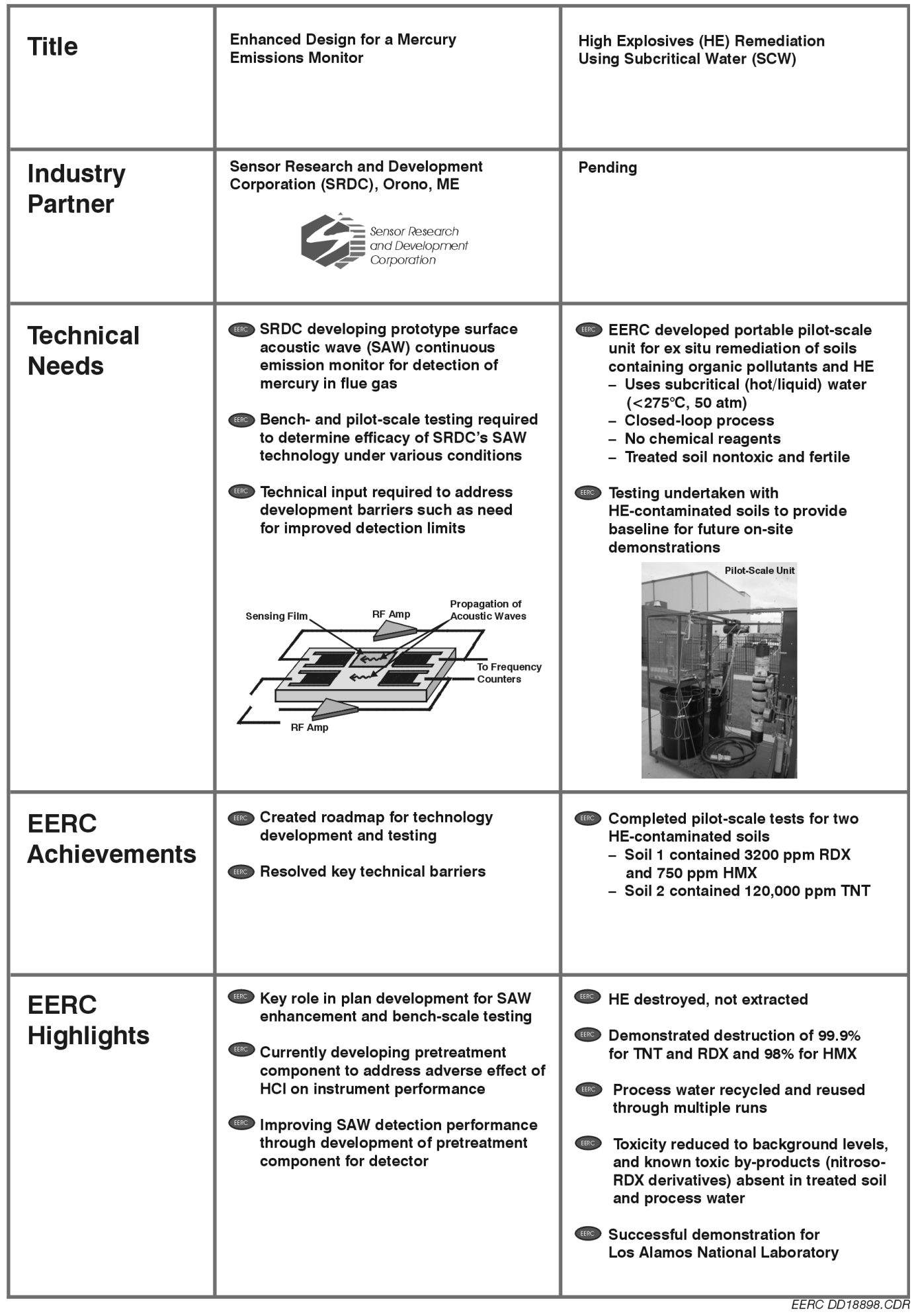

continued. . . 
TABLE 3 (continued)

Selected EM Technology Success Stories from the EERC

\begin{tabular}{|c|c|c|}
\hline Title & $\begin{array}{l}\text { Corrosives Removal from Vitrification } \\
\text { Feedstocks }\end{array}$ & $\begin{array}{l}\text { Volatile Metal Control Strategies } \\
\text { for Vitrification Operations }\end{array}$ \\
\hline $\begin{array}{l}\text { Industry } \\
\text { Partner }\end{array}$ & $\begin{array}{l}\text { GTS Duratek, } \\
\text { Columbia, MD }\end{array}$ & $\begin{array}{l}\text { Vortec Corporation, } \\
\text { Collegeville, PA } \\
\qquad \sqrt{\begin{array}{l}\text { ortec } \\
\text { Corporation }\end{array}}\end{array}$ \\
\hline $\begin{array}{l}\text { Technical } \\
\text { Needs }\end{array}$ & $\begin{array}{l}\text { GTS Duratek contracted to vitrify highly } \\
\text { alkaline tank wastes at Hanford site } \\
\text { Corrosives in waste can adversely } \\
\text { affect vitrifier performance } \\
\text { - Sulfate damages vitrifier electrodes } \\
\text { - Chloride damages vitrifier internals } \\
\text { and emission control components } \\
\\
\text { Conventional ion exchange, membrane } \\
\text { filtration, and other separation } \\
\text { technologies ineffective, uneconomical, } \\
\text { or unsafe for Hanford tank wastes } \\
\text { because of high levels of hydroxide, } \\
\text { nitrate, and nitrite and significant levels } \\
\text { of phosphate, chromate, and } \\
\text { complexed radionuclides }\end{array}$ & 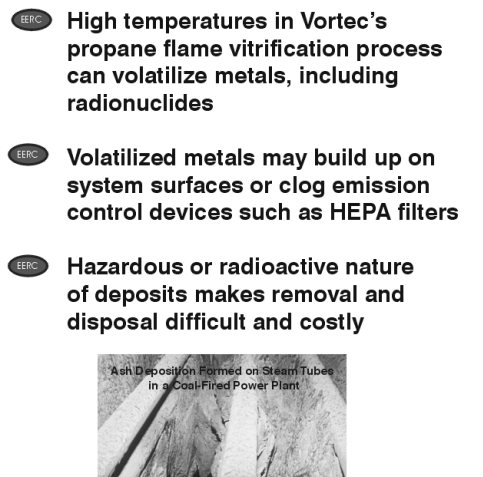 \\
\hline $\begin{array}{l}\text { EERC } \\
\text { Achievements }\end{array}$ & $\begin{array}{l}\text { Modified regenerable resin for } \\
\text { selective removal of sulfate and } \\
\text { chloride from highly alkaline tank } \\
\text { wastes }\end{array}$ & $\begin{array}{l}\text { Determined sampling protocols } \\
\text { (ax) Developed volatile metal control } \\
\text { strategies for vitrification operations } \\
\text { based on modeling using proven } \\
\text { thermochemical equilibrium codes }\end{array}$ \\
\hline $\begin{array}{l}\text { EERC } \\
\text { Highlights }\end{array}$ & $\begin{array}{l}\text { Achieved sulfate removal of } 99 \% \\
\text { through eight use-and-regenerate } \\
\text { cycles using highly alkaline } \\
\text { multicomponent Hanford tank } \\
\text { simulant prepared by GTS Duratek } \\
\\
\text { Exchange resin } 100 \% \text { regenerable } \\
\text { through eight cycles without bed } \\
\text { holdup of radionuclide surrogates }\end{array}$ & $\begin{array}{l}\text { Provided sampling and analysis plans } \\
\text { to support mass balance calculations } \\
\text { and system performance tests } \\
\text { Modeling identified variety of } \\
\text { radioactive elements that may } \\
\text { volatilize in propane flame of vitrifier } \\
\text { Modeling demonstrated efficacy of } \\
\text { simple remedies for volatilization } \\
\text { issues }\end{array}$ \\
\hline
\end{tabular}

continued. . . 
TABLE 3 (continued)

Selected EM Technology Success Stories from the EERC

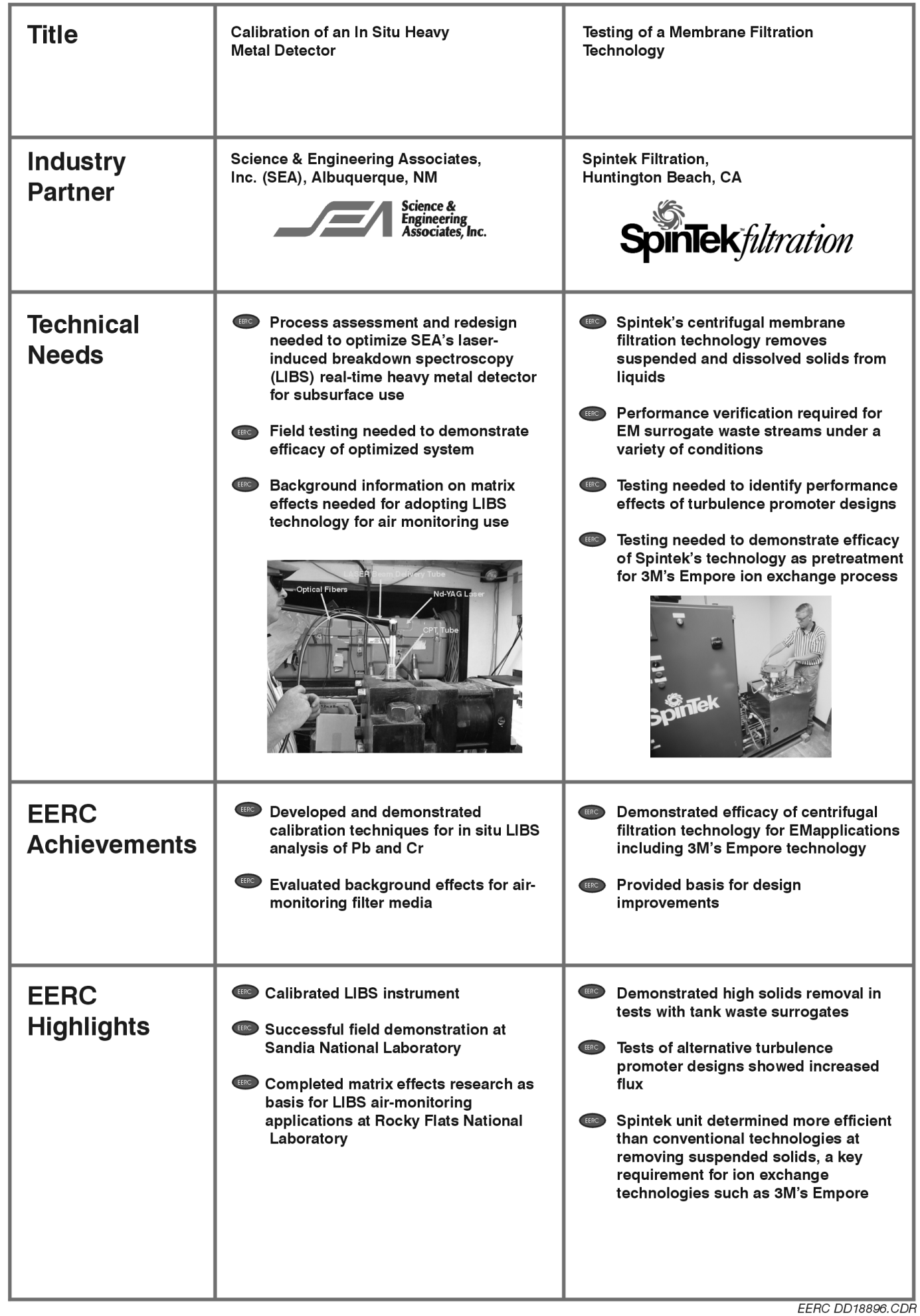


Strategic accomplishments include the following:

- The EERC provided technical assistance through EMCA tasks involving a total of 15 technologies.

- Of the 15 technologies, nine were with NETL industry partners, five were outside the NETL Industry Partners program, and one technology, Subcritical Water Treatment, is seeking an industry partner.

- Half of the technologies served under EMCA have been demonstrated at EM sites. Further, four of these seven technologies have either been deployed or are currently under serious consideration for deployment at EM sites.

- The EERC optimized EMCA program accountability, use to industry partners, and internal efficiency by assessing opportunities for integrating technologies into the DOE complex and external market.

EERC accomplishments under the individual technology commercialization tasks include the following:

- A prototype instrument for performing SFE (supercritical fluid extraction) with on-line FT-IR (Fourier transform infrared spectrometry) was developed, tested, and brought to the point of commercialization. Activities ceased when Suprex, the industry partner, was bought out by ISCO, its main competitor, and the SFE-FT-IR project was terminated.

- Plastics pyrolysis was demonstrated. The EERC had developed a low-temperature thermal decomposition process for volume reduction of high organic content waste from the nuclear defense complex. In tests with radioactive surrogates, chosen with assistance from Los Alamos National Laboratory, the EERC process was shown to be effective in concentrating radionuclide surrogates in a solids residual (e.g., $96.8 \%$ cesium surrogate) and yielding a nearly surrogate-free offgas or condensate product. The process was a modification of a technology for mixed postconsumer plastics treatment developed with the support of DOE, American Plastics Council, 3M, Amoco Chemical Company, and the U.S. Environmental Protection Agency (EPA).

- SpinTek Membrane Systems of Huntington Beach, California, was working to demonstrate the efficacy of a proven centrifugal membrane filtration technology adapted from the food preparation industry for use in the EM sector. As part of this activity, the EERC worked to enhance the performance of the SpinTek system and demonstrated the potential for using the SpinTek system as a pretreatment for the 3M Empore filter technology.

- F2 Associates of Albuquerque, New Mexico, was commercializing a laser-based surface coatings removal technology. The EERC demonstrated that the technology removed 
coatings with a low level of emissions, facilitated the selection of on-line sensors to provide feedback to the automated coatings-removal system, and developed a computer model to match coatings removal technologies to job requirements, including costs.

- Science \& Engineering Associates, Inc., of Albuquerque, New Mexico, was working to develop a laser-induced breakdown spectroscopy (LIBS) metal detection system for use in a cone penetrometer. As part of this effort, the EERC calibrated the LIBS, investigated the matrix effects on the calibration through multivariate analysis, and provided field support and assessment for field tests at Sandia National Laboratory and Hanford National Laboratory.

- Baumgartner Environics of Olivia, Minnesota, was developing a bubbleless gas transfer technology to accelerate in situ remediation of chlorinated hydrocarbons through efficient delivery of hydrogen gas to the subsurface. The EERC demonstrated the efficacy of this technology through laboratory column and batch experiments.

- The EERC has been developing a liquid (subcritical) water technology with applications for on-site cleanup of soils contaminated with high explosives. Under EMCA, the EERC constructed and tested a portable, field-ready pilot-scale unit.

- The Vortec cyclone melting system facility, proposed for the DOE Paducah Gaseous Diffusion Plant by Vortec Corporation of Collegeville, Pennsylvania, was designed to treat soil contaminated with low levels of heavy metals and radioactive wastes as well as organic wastes. The EERC prepared quality assurance/quality control sampling and analysis plans as a basis for determining compliance with EPA guidelines for emissions and the leachability of vitrified materials. The EERC also prepared a plan for testing and modeling of refractory corrosion, glass viscosity, and deposit formation to provide input for sound operating procedures. In addition, the EERC assisted the Vortec facility through computer modeling of chemical equilibria (e.g., vaporization and condensation of hazardous metals) using a thermochemical equilibria code specifically suited to this complex thermal system.

- The EERC undertook efforts to enhance the acoustic wave dense nonaqueous-phase liquid (NAPL) mobilization technology of Weiss Associates of Emeryville, Oklahoma, through laboratory tests coupling the Weiss technology with an environmentally benign humic acid surfactant developed at the EERC. The testing demonstrated that the use of humic acid surfactant coupled with acoustic excitation has the potential to improve the removal of NAPLs such as trichloroethylene from aquifers at a lower cost and with less environmental impact.

- Mercury Removal System Inc. of New Brighton, Pennsylvania, had developed a commercial thermal desorption process for the removal of mercury from soils and other solids. The EERC demonstrated the potential for cost savings through regenerable proprietary catalytic carbon with superior mercury removal potential, the testing of a variety of metal oxide sorbents, and the development and testing of a proprietary low- 
temperature mercury desorption method.

- ThermoChem Inc. of Columbia, Maryland, had developed a steam reforming process to treat low-level mixed wastes. The EERC helped demonstrate the environmental safety of the ThermoChem unit by confirming that $\mathrm{Cl}$ and $\mathrm{F}$ were collected in the baghouse, $\mathrm{Ce}$ was successfully contained in the high-efficiency particulate air filters and in the bed, and slag materials were environmentally benign.

- GTS Duratek of Columbia, Maryland, along with British Nuclear Fuels Ltd. has a contract to implement a vitrification system for highly alkaline tank wastes at the Hanford Site. Corrosives such as chlorine and sulfate adversely affect vitrifier performance. The EERC addressed this barrier by developing and testing a modified resin capable of selectively removing sulfate and chloride from the tank wastes prior to vitrification.

- Sensor Research and Development of Orono, Maine, is developing an innovative, solidstate, low-cost, portable surface acoustic wave (SAW) continuous emissions monitor for mercury vapor that functions in a variety of gas environments, including combustion gas streams. As part of this work, the EERC created a road map for technology development and testing, developed a pretreatment component to address the adverse effect of $\mathrm{HCl}$ on instrument performance, and improved SAW detection performance through the development of an additional pretreatment component.

- Phytoremediation is gaining popularity as a cost-effective means of dealing with lowlevel near-surface remediation issues, but posttreatment management of the plants has not been addressed on a large scale. In partnership with Phytokinetics, the EERC tested three posttreatment options: cofiring, extraction, and composting, on lead-contaminated plants. The EERC demonstrated that extraction was the best alternative with respect to environmental impacts and cost.

- Through an extensive search of modeling capabilities, the EERC found that the DIAMO uranium and processing group in the Czech Republic has an advanced model that could be applied to simulate complex environmental situations of the type encountered on U.S. Department of Defense and DOE sites. The EERC visited the DIAMO group and conducted a preliminary evaluation of the model, found it to be a powerful tool in its current form, identified specific areas requiring improvement, and recommended that the improvements be implemented and the model considered for use.

\section{Technology Support Accomplishments}

Under EMCA, the EERC undertook the following activities in support of NETL EM initiatives:

- The EERC undertook a literature survey and discussions with vitrification technologists to identify areas of concern for this technology. The activity indicated a lack of 
information in five topic areas. In addition, a literature survey was conducted to summarize studies on leaching from vitrification wastes and the relative use of waste stabilization technologies (including vitrification).

- The EERC acted as manager for a 3-year Technology Development Integration contract with Waste Policy Institute (WPI). Under this contract, WPI established and staffed technology support offices at five major EM sites.

- The EERC performed systems engineering for the DDFA, including cost modeling for D\&D technologies and a D\&D demonstration project at Hanford.

- The EERC developed focus tools to aid the DDFA. These included the Preferred Deployment Technology system, the on-line D\&D Information System, the updating of the overall DDFA database, and a draft methodology to prioritize D\&D sites.

\section{Management Accomplishments}

In addition to day-to-day management activities for the EMCA, the following were undertaken:

- Annual oral and poster presentations at NETL Industry Partners Meeting.

- Coordination of Annual EMCA project review meetings and oversight for preparation of the annual EMCA Continuation Application.

- Presentations and booth displays for the Biennial Spectrum Conferences and representation at other national conferences.

- Technology integration activities for select activities under the technology commercialization area and oversight of preparation of Technology Development Data Sheets. 


\section{APPENDIX A}

\section{TASK SUMMARIES FOR THE NETL-EERC EM COOPERATIVE AGREEMENT}




\section{Task 1- Provide Information Required for Compliance with the National Environmental Policy Act (NEPA)}

Industry Partner

None

Duration of Task

Fall 1995

Technology Integration Team

EERC Task Manager

John G. Hendrikson

A National Environmental Policy Act (NEPA) compliance document was required for this Cooperative Agreement. A NEPA compliance document was prepared in the fall of 1995. 


\section{Task 2 - Extraction and Analysis of Pollutant Organics}

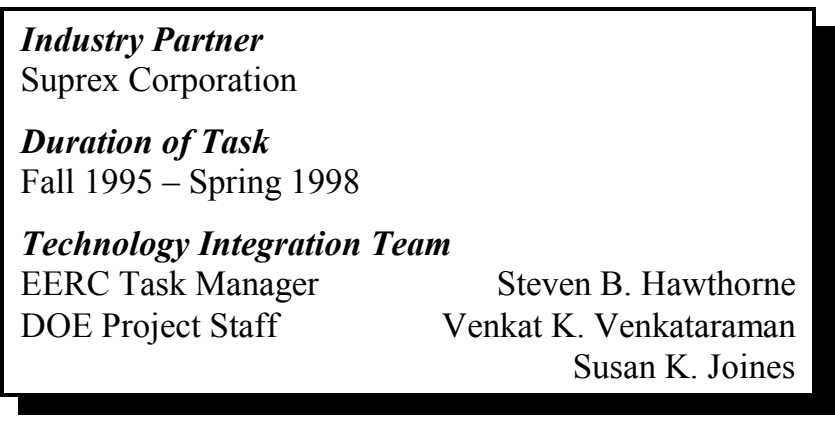

\section{Background and Objectives}

Organic pollutants, including fuel components, chlorinated solvents, ketones, polycyclic aromatic hydrocarbons (PAHs), and polychlorinated biphenyls (PCBs), are common soil contaminants at U.S. Department of Energy (DOE) and U.S. Department of Defense (DOD) facilities. Conventional methods to determine the type and concentrations of organic pollutants normally require transport of samples to a laboratory, extraction with large volumes of hazardous solvents, turnaround times of several days, and high cost.

The Energy \& Environmental Research Center (EERC) and the University of North Dakota (UND) Department of Chemistry developed a supercritical fluid extraction (SFE) field-portable method for quantitatively extracting organic pollutants (e.g., PAHs, PCBs, total petroleum hydrocarbons, and chlorinated solvents) from soils and sludges under U.S. Environmental Protection Agency (EPA) funding. Extracts can be collected off-line in a few milliliters of organic solvent and analyzed in the field or returned to the lab for conventional chromatographic analysis. Methods to perform both the extraction and analysis were developed by directly coupling SFE with Fourier transform infrared spectrometry (SFE-FT-IR). This approach yields ppm detection limits for organic contaminants, allows compound-class identification, can be used in the field, uses no organic solvent, and performs both the extraction and analysis steps in ca. 20 minutes or less. The SFE-FT-IR approach is particularly well-suited for on-site survey, since it should be possible to determine nearly all common organic pollutants found on DOE sites. The approach should also be valuable for samples contaminated with radioactive metals and organics, since organic pollutants can be determined without any waste solvent generation.

This activity under the DOE National Energy Technology Laboratory (NETL)-EERC

Environmental Management Cooperative Agreement (EMCA) was designed to develop a commercial version of a field-portable instrument for performing SFE with on-line FT-IR detection.

\section{Results}

A laboratory prototype SFE/FT-IR instrument was developed by the EERC and the UND Department of Chemistry (see figure). The interface instrument was field-portable (requiring only generator electricity) and able to extract and measure organic pollutants from soils and sludges, identify the compound classes present, and provide quantitative or semiquantitative results at detection limits relevant to regulatory needs (e.g., ppm). The instrument allows determinations to be made without generation of solvent wastes.

The instrument is also configured to allow collection of "positive" extracts for analysis by other confirmatory (e.g., gas chromatography-mass spectrometry [GC-MS]) methods.

The ability of SFE-FT-IR to yield correct identities of organic contaminant compound classes and to yield correct concentrations was compared to conventional extraction and analysis methods. Realworld soils, sediments, and sludges were analyzed for a range of organic contaminants (e.g., fuel hydrocarbons, PCBs, PAHs, chlorinated solvents). Robustness of the method in the field was evaluated against conventional methods at multiple sites.

- Prototype instrumentation yielded good quantitative comparisons with conventional methods.

- Detection limits of low ppm were demonstrated for a range of organic contaminants. 
- $\quad$ Prototype instrumentation was successfully used under field conditions.

- The commercial partner, Suprex Corporation of Pittsburgh, was bought out in 1998, and no additional vendor was identified.

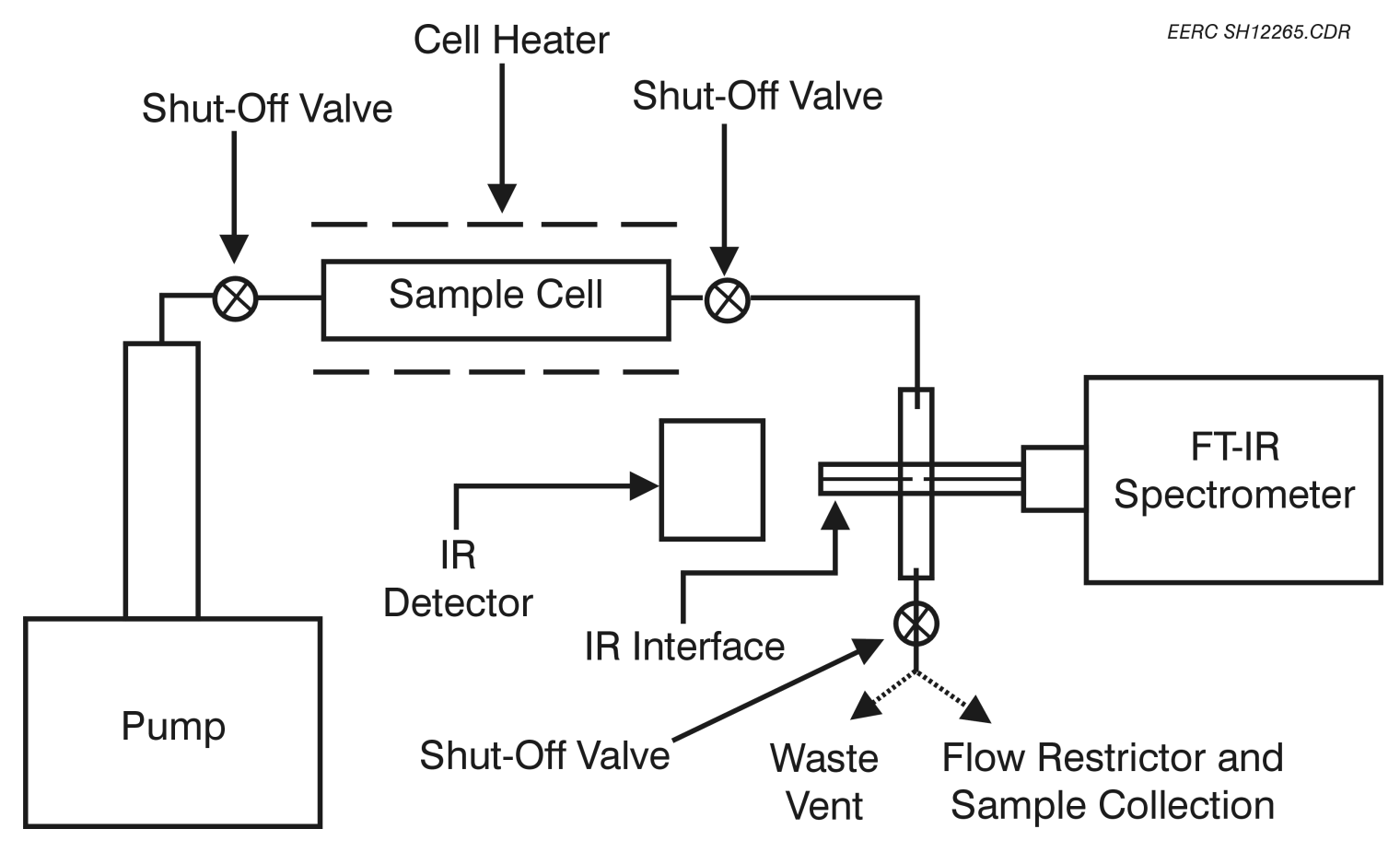

Prototype SFE-FT-IR 


\section{Task 3 - Pyrolysis of Plastic Waste}

\begin{tabular}{|c|c|}
\hline $\begin{array}{l}\text { Industry Partner } \\
\text { None }\end{array}$ & \\
\hline $\begin{array}{l}\text { Duration of Task } \\
\text { Fall } 1995 \text { - Spring } 1998\end{array}$ & \\
\hline $\begin{array}{l}\text { Technology Integration Team } \\
\text { EERC Task Manager } \\
\text { Principal Investigator }\end{array}$ & $\begin{array}{l}\text { Ted R. Aulich } \\
\text { Robert O. Ness }\end{array}$ \\
\hline
\end{tabular}

\section{Background and Objectives}

The EERC has developed a low-temperature thermal decomposition process for volume reduction of highorganic-content wastes from activities associated with nuclear defense and power generation, energy and manufacturing industries, medical practices, and biological research. The process evolved from work on thermal depolymerization of mixed-waste postconsumer plastics for production of fuel and chemical feedstocks sponsored by DOE, the American Plastics Council, 3M Company, Amoco Chemical Company, and EPA. Motivation for commercial application of the process to radioactive waste volume reduction is provided by the cost of Class A nuclear waste landfill disposal, which is about $\$ 400 / \mathrm{ft}^{3}$.

Primary project objectives were to optimize the thermal decomposition process for application to volume reduction of 1) high-organic-content radioactive mixed wastes and 2) spent (radioactive) ion-exchange resins from nuclear power facilities. Stone \& Webster Environmental Technology \& Services, Boston, Massachusetts, was retained by the EERC to provide data and information regarding nuclear industry waste generation and wasteprocessing needs. Using radionuclide surrogates selected with assistance from Los Alamos National Laboratory (LANL), tests were performed using the EERC laboratory-scale (1-4-lb/hr) continuous fluidbed reactor system. Tests were also performed using the EERC laboratory-scale auger reactor system to evaluate the effect of a lower purge gas flow rate (versus a higher fluidization gas flow rate) on particulate entrainment and postreactor gas treatment requirements. Test feedstocks included surrogatespiked mixtures of postconsumer plastics and cesium- loaded commercial-grade ion-exchange resin. The resin was supplied by GTS-Duratek, a commercial nuclear waste-processing company headquartered in Columbia, Maryland, with an interest in commercial application of the EERC polymer decomposition process. Throughout the project, Duratek consulted with and provided information to the EERC regarding desired process throughput and related work on resin processing.

\section{Results}

Test results demonstrated that the EERC process is effective in concentrating radionuclide surrogates in a solids residual and yielding a nearly surrogate-free offgas or condensate product. Control of sulfur and chlorine emissions was also demonstrated with the use of a temperature-controlled postreactor packed-bed filter containing alkaline material. In fluid-bed tests with feedstock mixtures of waste plastics and nine surrogate species added in concentrations of about 1000 to $3000 \mu \mathrm{g} / \mathrm{g}$, product analyses indicated that with the exception of tin, which has a boiling point of about $232^{\circ} \mathrm{C}$, all surrogates were concentrated in the solids residual but that some carryover into the offgas stream occurred. In all cases, the small quantities of surrogates observed in the fluid-bed offgas streams were removable by filtration, which indicated particulate carryover by fluidization gas stream entrainment. In tests with an auger reactor, which enabled the use of a lower-velocity gas flow (since fluidization was not required), surrogate carryover was significantly reduced. In an auger reactor test conducted at about $550^{\circ} \mathrm{C}$ with an ion-exchange resin loaded with $1960 \mu \mathrm{g} / \mathrm{g}$ of cesium, the following key results were achieved:

- Volume reduction without crushing or compaction: $79 \%$

- Cesium content of total offgas: $29.9 \mu \mathrm{g} / \mathrm{L}$

- Portion of cesium recovered in solids residual: $96.8 \%$

- Portion of cesium recovered in offgas: $2.1 \%$ 
- Cesium closure based on calculated mass balance: $98.9 \%$

\section{EM Application}

Based on the work performed during this and prior projects, it appears that the auger reactor configuration has significantly higher potential for applications in which quantitative separation and recovery of radionuclides and/or heavy metals (both inorganically and organically associated) are important. Based on discussions with Duratek and other industry personnel regarding application of the EERC process to radiative waste streams, key viability criteria include:

- Achievement of an approximately 8-to-1 waste volume reduction.

- Concentration of $99.9 \%$ to $99.99 \%$ of feedstock-contained radionuclides into a solids residual.

- Generation of a solids residual with a sulfur content of about $1 \%$ and a minimum carbon content.
- Demonstration of an economic system for monitoring and preventing radionuclide emissions.

- Demonstration of adequate sulfur emission control.

- Development and demonstration of an economic system for preprocess feedstock drying that enables continuous feeding.

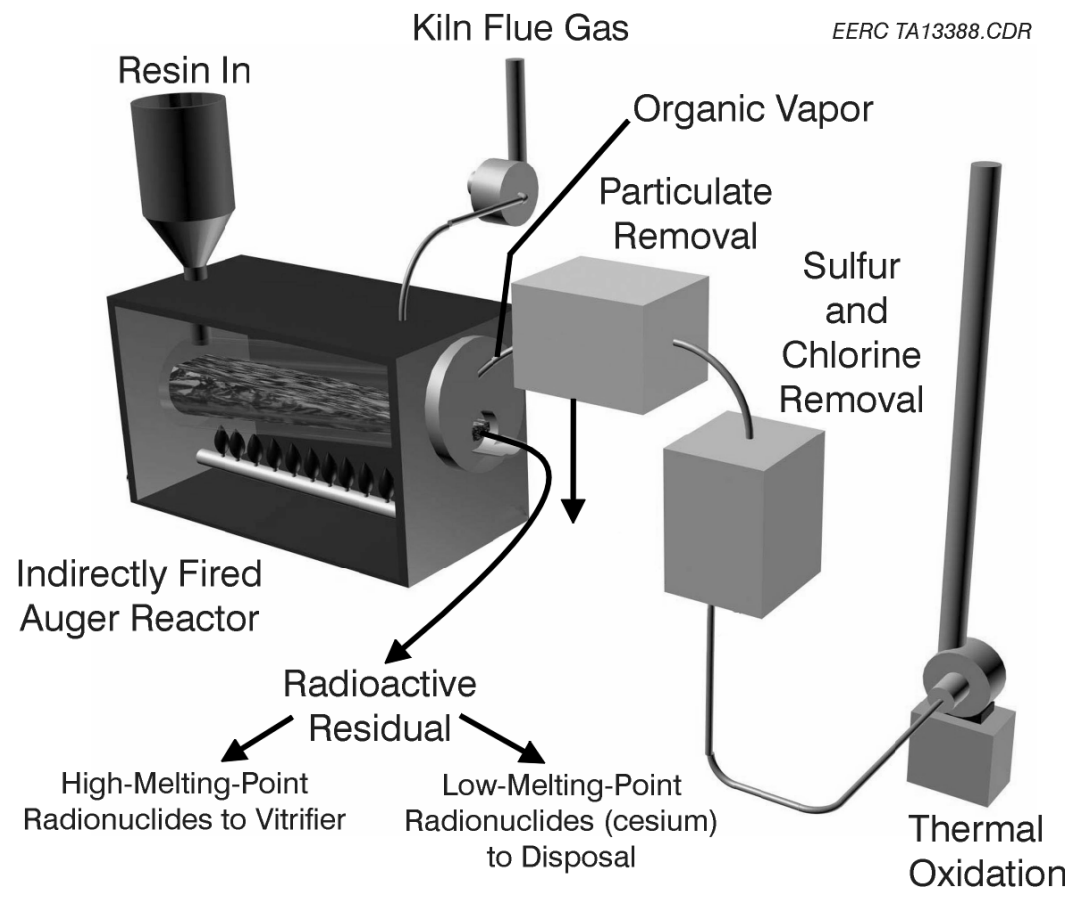

Auger-Reactor-Based Process for Volume Reduction of Radioactive Ion-Exchange Resin and Other Organic Wastes 


\section{Task 4 - Stabilization of Vitrified Waste by Enhanced Crystallization and Development of a Protocol to Predict Long-Term Stability}

\begin{tabular}{|c|c|}
\hline \multicolumn{2}{|c|}{$\begin{array}{l}\text { Industry Partner } \\
\text { U.S. Department of Energy National Er } \\
\text { Technology Laboratory, Morgantown }\end{array}$} \\
\hline $\begin{array}{l}\text { Duration of Task } \\
\text { September } 1994 \text { - Oct }\end{array}$ & 1995 \\
\hline Technology Integratio & eam \\
\hline EERC Task Manager & John P. Hurley \\
\hline Principal Investigators & $\begin{array}{r}\text { Jan W. Nowok } \\
\text { Debra F. Pflughoeft-Hassett }\end{array}$ \\
\hline Project Staff & David J. Hassett \\
\hline
\end{tabular}

\section{Background and Objectives}

Simply vitrifying a material into a glassy slag does not necessarily produce an environmentally stable product. The chemistry of the materials must be assessed and, if necessary, modified with additives and nucleation agents. The incorporation of toxic metals and radionuclides into stabilized phases must also be determined. The ability of a material to produce stable phases is largely dependent upon chemical composition, time, and temperature.

The specific objective of this project was to perform literature surveys and hold discussions with vitrification system providers to identify areas of specific concern that could be the subject of subsequent development work.

\section{Results}

A literature review was completed that provides an overview of low- and high-level nuclear waste immobilization. The objective of the survey was to concisely summarize glass properties with nuclear wastes and/or hazardous elements for their effective immobilization and to specify directions of further tests to produce durable and highly stable glasses. Emphasis was on technologies based on borosilicate glasses, since this glass will be used in the United States and Europe to immobilize radioactive highlevel liquid wastes for ultimate geological disposal.
Vitrification of aqueous radioactive wastes can achieve large volume reductions (86-97 vol\%) and will ensure their stabilization. Borosilicate waste glasses are the most studied and probably best understood waste form that has been developed. The application of synrocs, cements, and bentonites for radionuclide immobilization was also explored.

This survey indicated a lack of information in the following areas:

- Vaporization of heavy or radioactive metals from the melts and whether vaporization behavior could be controlled by modifying the heating environment in order to separate the hazardous materials from the bulk waste.

- How to avoid the formation of molten sodium sulfate on the cold cap.

- Catalytic activity of radionuclides at the surface of the glass and glass corrosion in water.

- The effect of glass-cooling rate on generation of residual stresses below the temperature of glass transformation and its effect on the leachability of nuclear waste glass.

- The effect of foaming of the melt on the homogenization of nuclear waste during vitrification using plasma technology.

In addition, a two-pronged literature survey of cleanup sites was completed, focusing on studies of the leaching of vitrified wastes at the sites as well as a general survey of existing DOE hazardous waste sites and waste stabilization technologies (other than vitrification) that are currently in use at the sites. A preliminary assessment of leaching studies indicated that the testing procedures currently used to determine the leachability of the waste materials were geared to 
short-term procedures directed toward regulatory compliance rather than realistic or predictive testing.

The survey of DOE waste sites was part of this larger survey. The information reviewed indicated a wide variety of mixed wastes containing low-level nuclear material or radionuclides. Some of the wastes are suited for vitrification, while others would be better stabilized with alternative technologies because of the nature of some of the constituents. These include mixed wastes with chlorinated hydrocarbons, explosives, and pesticides. These wastes were not considered in this project.

\section{EM Application}

This project contributed to DOE's identified technical needs in waste characterization, low-level mixedwaste processing, disposition technology, and improved waste forms. 
Task 5 - Extraction of Hazardous Metals from Mixed Solid Wastes by Chelation and Supercritical Fluid Extraction

Task 6 - Subcritical Water Extraction of Organic Pollutants

Task 7 - Demonstration of a Low-Temperature Plasma Remediation Technology

Tasks 5-7 were proposed in Year 2 but were not funded because the EERC was directed to pursue partnerships with established NETL industry partners. 


\section{Task 8 - Integration, Management, and Reporting}

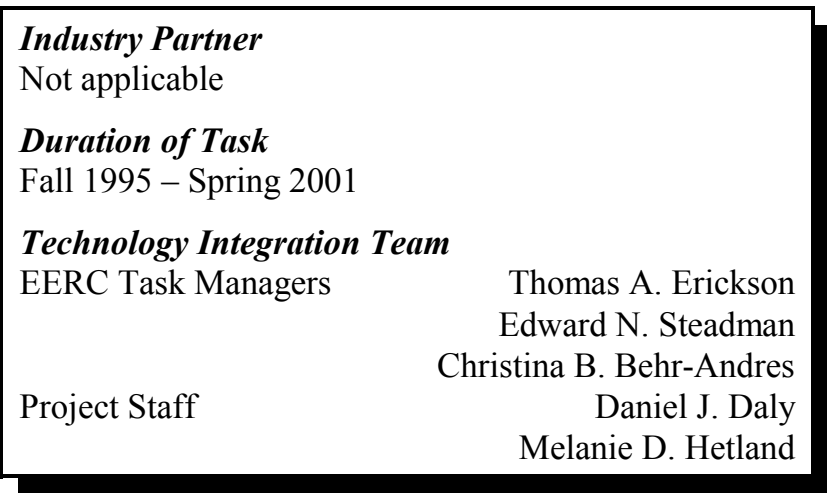

In addition to the overall management and planning for the EMCA, the following activities were undertaken:

- Annual NETL industry partners' meetings: Each year since EMCA was initiated, the EERC has prepared a presentation and written contribution titled "Environmental Management Technology Demonstration and Commercialization" for the NETL Industry Partners' Meeting held each October at NETL, Morgantown, West Virginia.

- Annual EMCA project review meetings: Logistics and the preparation of materials were coordinated under Task 8 for the annual EMCA project review. Meeting locations have alternated between NETL and the EERC.

- Annual EMCA continuation applications: Each year, the preparation of the EMCA continuation application has been coordinated through Task 8. Activities have included marketing to NETL industry partners, support to technical staff in developing individual tasks, coordination with NETL in assessing and choosing candidate tasks, and overseeing the preparation and submittal of the continuation application.

- Papers and booth materials have been prepared under Task 8 for the Biennial Spectrum Conferences. The EERC prepared a paper and set up a display booth at Spectrum '96 (Seattle, Washington, October 1996). The EERC also prepared and submitted a paper for Spectrum '98 (Denver, Colorado, October 1998).

- Under Task 8, EMCA was represented at a number of other national conferences including 1) ER ' 95 held in Denver, Colorado, August 13-16, 1995; 2) the Applied Research and Cleanup Technology Colloquium, held in Phoenix, Arizona, April 29-May 2, 1996 (presented a paper titled "Dynamic Partnership: Facilitating EM Technology Development and Deployment"); 3) the XChange ' 97 Conference in Florida in December 1997; 4) the 2006 Plan meeting held May 11-12, 1998, in Washington, DC; the Mixed Waste Mercury Workshop held in Atlanta, Georgia, November 18-20, 1998; 5) the Applied Research, Development, and Deployment Colloquium held in Scottsdale, Arizona, in early May 1999; 6) the ER-TEC meeting in Charleston, South Carolina, June 9-10, 1999; 7) the Spectrum 2000 (Chattanooga, Tennessee, September 2000); and 8) the Weapons-Complex Monitor, Decisionmaker's Forum, held at Amelia Island, Florida, October 2000.

- Technology integration activities for select tasks were performed under Task 8. Activities included providing a listing of key NETL, industry partner, and DOE complex contacts, a listing of potential applications within the EM complex, a listing of competing technologies, and a comparison of key features between EMCA and competing technologies. This information was compiled and organized in "technology sourcebooks," which were distributed to the task managers.

- Under Task 8, activities and progress under 
the EMCA program were profiled through the semiannual preparation of an updated Technology Development Data Sheet. 


\section{Task 9 - Centrifugal Membrane Filtration}

\begin{tabular}{|lr|}
\hline Industry Partner & \\
SpinTek Membrane Systems & \\
Duration of Task & \\
September 1994 - December 1998 & \\
Technology Integration Team & \\
EERC Task Manager & Daniel J. Stepan \\
Project Staff & Michael E. Collings \\
& Thomas A. Erickson \\
& Melanie D. Hetland \\
& Marc D. Kurz \\
& Thomas A. Moe \\
& Bradley G. Stevens \\
Rodney S. Stoa \\
Students & Michael E. Grafsgaard \\
& Theo N. Kestner \\
\hline
\end{tabular}

\section{Background and Objectives}

The DOE has a critical need to minimize the volume of the liquid mixed-waste streams that occur at the various weapons complex sites so that remediation of these waste streams is more cost-effective. SpinTek Membrane Systems, Inc., owns a novel centrifugal membrane filtration technology that makes use of ultrafiltration and centrifugal force to separate suspended and dissolved solids from liquid waste streams, producing a filtered liquid stream and a lowvolume contaminant-concentrate stream. The EERC assisted SpinTek in the continued development of its process by modifying the SpinTek system to enhance filtration performance; by comparing the effectiveness of SpinTek's filtration with that of traditional filters, especially when placed prior to a technetium-removal cartridge designed by $3 \mathrm{M}$; and by performing a preliminary cost analysis for the use of the SpinTek system as a waste-minimization technique.

\section{Results}

Variations in turbulence promoter design were evaluated to determine their effect on filtration performance. The alternate designs were developed using an analysis of flow patterns within the filter chamber. Minimization of filter cake deposition is essential to the success of a crossflow filter system, and this can be accomplished by minimizing the disk boundary layer thickness. Three techniques for minimizing the thickness of the disk boundary layer were evaluated: the clearance between the membrane and the turbulence promoter was reduced, the promoter blades were angled to increase fluid circulation within the filter chamber, and the promoter blades were beveled. Statistically designed experimental matrices were used to evaluate the different turbulence promoter configurations. The results indicated that although the tests performed using the nonbeveled promoters were not performed at the same solids loading as the tests of the beveled promoter, the permeate flux rate was greater and the power consumption lower for the beveled promoter. It is unknown to what degree the different slurry solids loadings might have affected the permeate flux and the power consumption.

An economic analysis was performed to determine the approximate cost of filtering 1 gal of liquid waste with the SpinTek system and to compare this cost to the cost of other, competing technologies. The information can be used to identify situations in which the SpinTek technology could be most effectively applied. It was found that the cost of using SpinTek technology compares favorably with other ultrafiltration technologies that are currently available and that the choice of using SpinTek rather than another technology would depend on a number of factors, including waste volume and contaminant type and concentration. Because its use is not limited to specific contaminants, the SpinTek process is applicable to a wider variety of liquid waste streams than the other technologies.

SpinTek's filtration is a crosscutting technology with a number of applications for cleanup of DOE weapons complex liquid wastes. One application is the enhancement of downstream unit operations such as adsorption or ion-exchange processes where even low levels of suspended solids create operation problems. Tests were performed to evaluate the use of SpinTek filtration as a prefiltration prior to a $3 \mathrm{M}$ technology that selectively removes dissolved radionuclides from liquid wastes. The $3 \mathrm{M}$ technology is limited by the quantity of suspended materials contained in the waste 
stream, which can cause plugging well before its radionuclide-removal capability is exceeded. Three types of tests were performed: without filtration, with prefiltration using conventional cartridge-style paper filters, and with prefiltration by SpinTek centrifugal membrane filtration. The results showed that prefiltration was required for effective operation of the $3 \mathrm{M}$ technology and that the SpinTek prefiltration was much more efficient at removing suspended solids than prefiltration using conventional cartridge-style filters. Because of their minimal cost, conventional paper prefilters may be adequate for filtration of small volumes or low suspended solids content. As waste volumes and the suspended solids loading increase, economics begin to favor the more effective SpinTek prefiltration.

\section{EM Application}

According to current DOE EM needs, 90.6 million gallons of tank waste require treatment. SpinTek filtration could also be applied to the remediation of contaminated groundwater plumes, the treatment of secondary liquid waste streams from other remediation processes, and filtration of the liquid waste streams generated during deactivation and decommissioning (D\&D) activities. 


\section{Task 10 - Technology Development Integration}

\begin{tabular}{|c|c|}
\hline $\begin{array}{l}\text { Subcontractors } \\
\text { Waste Policy Institute and Van }\end{array}$ & ss Feldman \\
\hline $\begin{array}{l}\text { Duration of Task } \\
\text { July } 1995 \text { - September } 1997\end{array}$ & \\
\hline $\begin{array}{l}\text { Technology Integration Team } \\
\text { EERC Task Manager } \\
\text { Project Staff }\end{array}$ & $\begin{array}{r}\text { Daniel J. Daly } \\
\text { John G. Hendrikson }\end{array}$ \\
\hline
\end{tabular}

\section{Background and Objectives}

Under Task 10, the EERC provided management and oversight to a Waste Policy Institute activity, Environmental Management Technology

Development Integration, that was set up "to develop, demonstrate, and commercialize technologies that address environmental management needs of contaminated sites" together with "management activities which accelerate transfer of technologies." The work was divided into three activities:

- Task 10.1 Technology Management Technical reviews of requirements, needs, and assessments related to waste characterization, containment, in situ and ex situ treatment, waste storage, disposal, robotics handling, monitoring, laboratory analysis, and site characterization and remediation activities were performed.

- Task 10.2 Project Management - Participants conducted reviews and analyzed and developed strategies for program management systems to integrate and control programs, projects, tasks, and documentation.

- Task 10.3 Technology Integration - Criteria for identifying risks to public health and safety posed by conditions at weapons complex facilities were established, the extent of these risks evaluated, the urgency and priorities for eliminating or minimizing the risks determined, and the cost of activities required to meet applicable compliance agreements assessed.

\section{Results}

Technology integration support offices were established and staffed at the five major EM sites. Offices provided technical support to major EM focus area lead organizations in the areas of technology management, project management, and technology integration. 


\section{Task 11 - Systems Analysis of Environmental Management Technologies}

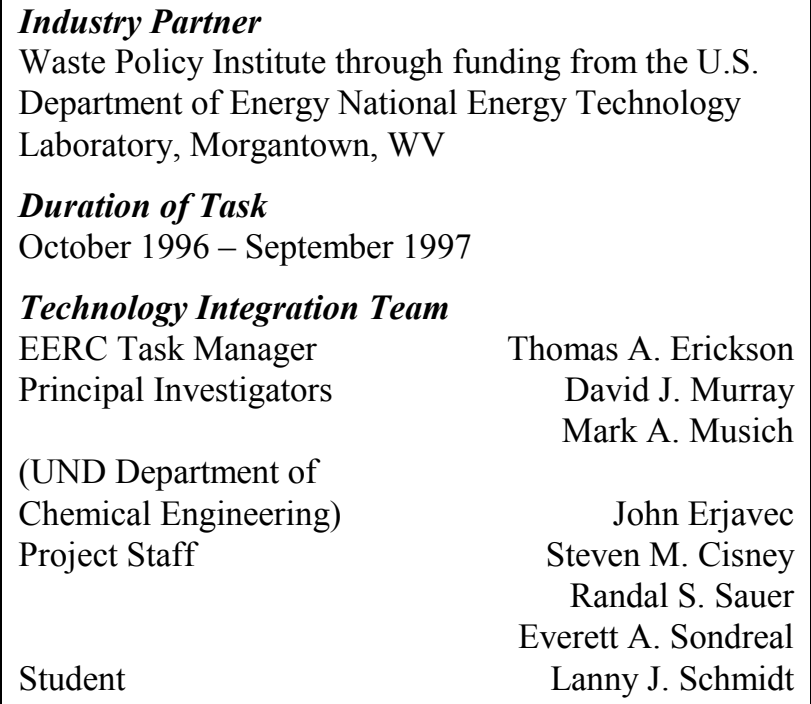

Waste Policy Institute through funding from the U.S. Department of Energy National Energy Technology Laboratory, Morgantown, WV

Duration of Task

October 1996 - September 1997

Technology Integration Team EERC Task Manager

Principal Investigators

(UND Department of

Chemical Engineering)

Project Staff

Student

Thomas A. Erickson David J. Murray Mark A. Musich John Erjavec Steven M. Cisney Randal S. Sauer Everett A. Sondreal Lanny J. Schmidt

\section{Background and Objectives}

The DOE has proposed a target date of 2006 to clean up the majority of all weapons development sites. Systems engineering and systems analysis can be used to identify and develop financially beneficial technologies. The EERC provided systems engineering and systems analysis support to DOE to assist in the rapid commercialization of cleanup technologies.

\section{Results}

Two large studies and numerous smaller projects were performed. The first large study consisted of reviewing a model that generates costs for $D \& D$ technologies. Seven different scenarios for cleaning up buildings were evaluated. The results were used to develop a more useful model.

The second large study involved the economics of a demonstration project at the Hanford site in Washington. The economics of various scenarios were studied to determine the funding strategy for the demonstration.

\section{EM Application}

The use of systems engineering to help guide the development of technologies is becoming more common and more beneficial. With the current suite of systems engineering tools available and the knowledge base of EM projects, systems engineering is providing the federal government with a powerful tool to attain its cleanup goals. 


\section{Task 12 - Laser Cleaning of Contaminated Painted Surfaces}

\section{Industry Partner}

F2 Associates Incorporated

\section{Duration of Task}

December 1995 - December 1997

Technology Integration Team

EERC Task Manager

Project Staff

Student
Ames A. Grisanti

Sean E. Allan

David J. Hassett

Charlene R. Crocker

Robert R. Jensen

Benjamin L. Kadrmas

\section{Background and Objectives}

Surface decontamination of concrete and steel surfaces in nuclear facilities provides cost savings during decommissioning operations by allowing recycling or reuse of concrete and steel structures. Separation of radionuclides and other contamination from the concrete or steel substrates also reduces the volume of hazardous materials during the $\mathrm{D} \& \mathrm{D}$ process, resulting in further cost savings.

Several techniques are available or under development for surface decontamination in nuclear facilities. Each technique has its merits; however, none of them is universally the best choice for all surface decontamination applications. Some issues which confront an organization selecting a surface decontamination technique for a particular application include the following:

- Project scale

- Concrete or metal surfaces

- Contamination by radiological and other hazardous materials

- Stage of surface decontamination technology development (e.g., commercial, research and development)

- Equipment operating costs

- Collection of waste generated by surface decontamination

- Occupational health and safety requirements

- Utilities required for operations

- Real-time control of surface decontamination

- Recycling or reuse of decontaminated substrates

- Waste

- Characterization

- Classification

- Transport

- Storage

- Treatment

- Disposal

- D\&D equipment decontamination

Because of the multitude of factors which influence the environmental and economic aspects of selecting a surface decontamination technique, it is difficult to select the best method in a given situation; an objective basis for comparing techniques is needed.

The objective of this project was to develop a software tool for use by personnel selecting a surface decontamination technique. The software incorporates performance data for available surface decontamination techniques.

\section{Results}

A decision tree was developed to permit the overall process of surface decontamination for a given technology. Complex procedures such as those involving waste classification, storage, transport, and treatment were paid special attention when the decision tree was developed.

A database of available literature relating to surface decontamination operations was completed. All literature in the database is on file in hard copy or microfiche. Initial review of all articles was used to determine which were the most pertinent to surface 
decontamination systems analysis. Detailed review and compilation of information from the articles were also completed.

Data on surface decontamination operations were gleaned from available reports. Several articles contained evaluations of surface decontamination techniques for specific cases. Data were compiled from a number of articles and put into a form that permitted comparisons to be made. For example, the accompanying chart comparing surface-cleaning technologies was derived from literature data.

A systems model of surface decontamination operations was developed. An easy-to-use software package incorporating both the surface decontamination model and a database containing performance data for applicable technologies has been completed and is currently undergoing sensitivity testing.

\section{EM Application}

The software developed under this project will allow personnel evaluating surface decontamination options to do a systematic comparison of technologies to select the one offering the greatest potential for substantial cost savings.

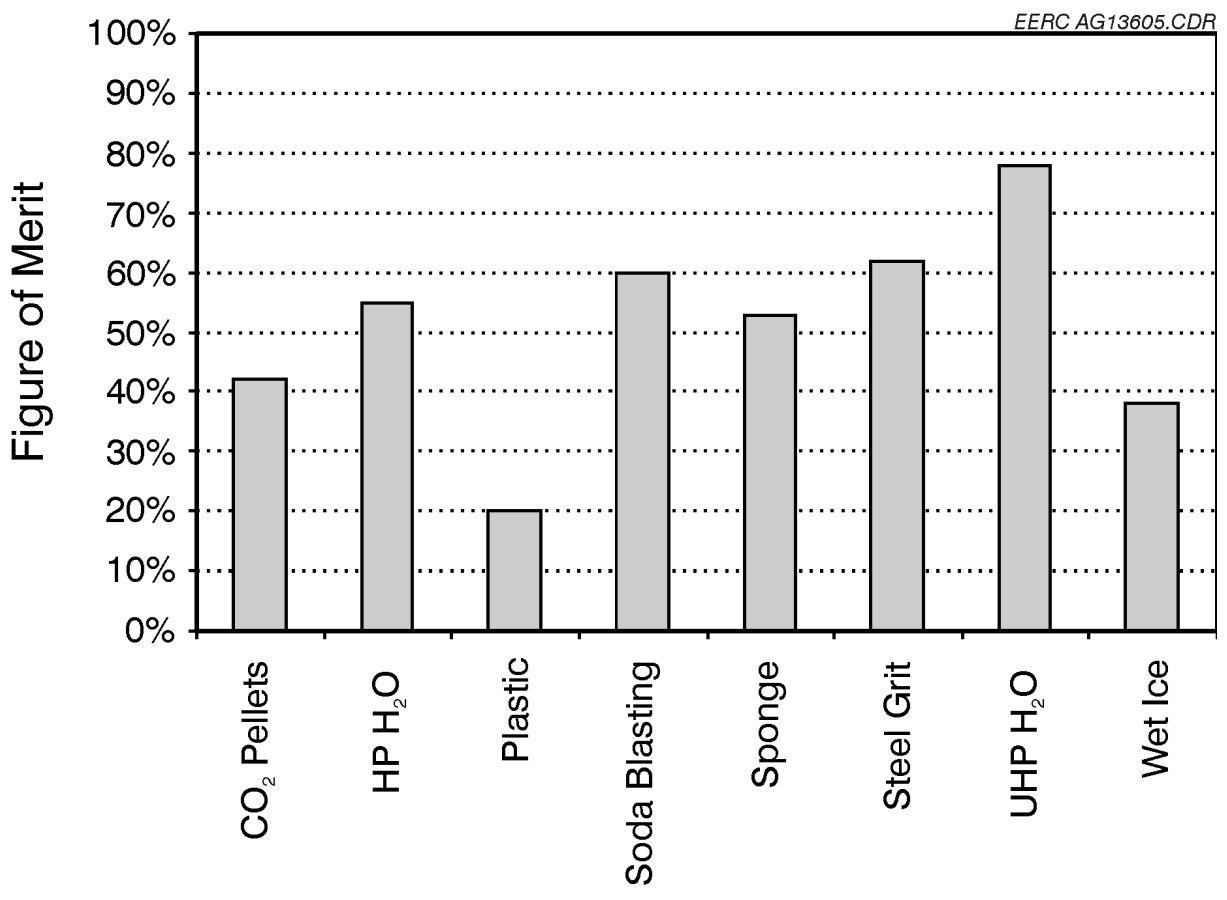

Figure of Merit for Various Surface Decontamination Techniques Applied to Painted Plate and I-Beams 


\section{Task 13 - Cone Penetrometer for Subsurface Metal Detection}

\begin{tabular}{|lr|}
\hline Industry Partner & \\
Science \& Engineering Associates & \\
Duration of Task & \\
December 1996 - December 2000 & \\
Technology Integration Team & \\
EERC Task Manager & Ames A. Grisanti \\
Project Staff & Charlene R. Crocker \\
& Kurt E. Eylands \\
& Curt L. Foerster \\
& Bethany A. Bolles \\
& Ronald C. Timpe \\
Student & David G. Westerman \\
& Mark D. Sayler \\
\hline
\end{tabular}

\section{Background and Objectives}

Surface and subsurface contamination of soils by heavy metals, including $\mathrm{Pb}, \mathrm{Cr}, \mathrm{Cu}, \mathrm{Zn}, \mathrm{As}$, and $\mathrm{Cd}$, has become an area of concern for many industrial and government organizations. Conventional sampling and analysis techniques for soil provide a high degree of sensitivity and selectivity for individual analytes. However, obtaining representative sampling and analysis from a particular site using conventional techniques is time-consuming and costly. Additionally, conventional methods are difficult to implement in the field for in situ and/or real-time applications. Therefore, there is a need for characterization and monitoring techniques for heavy metals in soils which allow cost-effective, rapid, in situ measurements.

Laser-induced breakdown spectroscopy (LIBS) has been used to successfully measure metals content in a variety of matrices, including soil. Under the DOE NETL industry program, a subsurface cone penetrometer (CPT) probe for heavy metals detection that employs LIBS has been developed. The LIBS-CPT unit can be applied to in situ, real-time sampling and analysis of heavy metals in soil.

The overall objectives of this project were to evaluate potential calibration techniques for the LIBS-CPT instrument, to provide a preliminary evaluation of the LIBS instrument calibration using samples obtained from the field, and to assist with field demonstrations for the LIBS-CPT system.

\section{Results}

In order to obtain data that allow laboratory preparation of soil mixtures representative of the field site, the following activities were performed: 1) evaluating inductively coupled plasma (ICP), graphite furnace atomic absorption spectroscopy (GFAAS), and wavelength-dispersive $x$-ray fluorescence (WDXRF) analytical methods for quantitation of metals in soils; 2) collecting field samples to be analyzed against LIBS calibration; 3 ) defining procedures for laboratory-prepared soil mixtures; and 4) collecting appropriate baseline soil from which to create a suite of calibration samples.

A limited evaluation of laboratory analytical methods was initially performed using National Institute of Standards and Technology standard reference materials. These data were later augmented with the analysis of field samples by separate laboratories using destructive and nondestructive sample preparation techniques.

Soils containing a range of heavy metal concentrations were collected from two abandoned ore mill tailing sites in western Montana. Extracted cores from seven bore holes were partitioned into discrete soil samples at depth intervals of approximately 1 foot, resulting in 151 samples. A subset of 66 samples that encompassed a range of soil types was selected for detailed analysis. Using ICP-GFAAS and WDXRF, the samples were analyzed for $\mathrm{As}, \mathrm{Cd}, \mathrm{Cr}$, $\mathrm{Cu}, \mathrm{Fe}, \mathrm{Pb}$, and $\mathrm{Zn}$ by the EERC analytical laboratories. To aid in the calibration of the LIBS instrument for analysis of the Montana samples, a baseline soil was chosen that has a mineral content, humic matter content, and $\mathrm{pH}$ similar to that of the Montana sediment samples. A suite of 81 different calibration soils was prepared by spiking the baseline soil with varying amounts of $\mathrm{As}, \mathrm{Cu}, \mathrm{Pb}$, and $\mathrm{Zn}$. The heavy metals concentrations in the spiked soils were 
verified using ICP and WDXRF.

EERC researchers developed computer algorithms for processing raw LIBS data that deliver improved prediction precision and accuracy of estimated heavy metal concentrations in soil. Calibration and sample soils data collected using a portable prototype LIBS unit (Spark ID $^{\mathrm{TM}}$ ) were reduced using custom routines developed at the EERC to export the LIBS spectra into software that allows the user to develop calibrations, select and reduce data, and determine analyte concentration using principal component analysis. The accompanying figure compares the calibration of the same sample data processed through conventional peak area analytical techniques and through the EERC method known as PLS calibration. This data reduction technique was used successfully to reduce data collected from the LIBS-CPT unit as well.

EERC personnel worked with SEA and Sandia Laboratories personnel over the week of July 13, 1998, on a field demonstration of the LIBS-CPT system at the Area 111 Chemical Waste Landfill at Sandia. The application of the LIBS-CPT unit was to perform a subsurface survey for chromium contamination in the soil. Several personnel involved in environmental restoration activities at DOE facilities witnessed the field demonstration. Overall, the field demonstration was a success. Core samples from the site had been previously collected and analyzed for metals using GFAAS and/or ICP by Sandia National Laboratory personnel. Chromium and $\mathrm{Fe}$ concentrations were found to range from approximately 50 to $2500 \mathrm{ppm}$ and from 10 to $20 \mathrm{ppm}$ (by weight), respectively, at depths of 10 to 20 feet. The LIBS-CPT was implemented at this site, and spectra were collected at depth intervals of approximately 0.1 inches. Assuming that the Fe concentrations measured by Sandia were constant over the depth interval, the iron peaks were used as an internal standard for comparison of $\mathrm{Cr}$ peak intensities. Using this calibration technique, the LIBS-CPT was able to successfully detect and estimate quantities of $\mathrm{Cr}$ in the subsurface.

Experiments to determine the feasibility of using LIBS to determine $\mathrm{Pb}$ content in paint and elemental percentage in metal alloys were conducted. EERC personnel also evaluated the effectiveness of LIBS for analyzing beryllium $(\mathrm{Be})$ deposited on air sample filters, particularly with regard to matrix effects on such analyses. Results showed that while LIBS could be used to effectively detect the presence of $\mathrm{Be}$ on air sample filters, other airborne contaminants commonly associated with demolition activities, such as iron rust, concrete dust, and gypsum particles, can significantly impact Be quantitation.

\section{EM Application}

Contamination of the subsurface by heavy metals presents a widespread problem across the United States, especially at DOD and DOE sites. LIBS, coupled with CPT, has the potential to facilitate substantial cost savings in field-screening and contaminant delineation applications. The ability to detect and quantify $\mathrm{Pb}$ in coatings could be useful to DOE personnel characterizing buildings for decontamination and demolition. Use of LIBS technology to identify the specific element content of alloys present in scrap metal at demolition sites could enhance potential resource recovery. The EERC work also showed that there is potential for the use of LIBS for analyzing $\mathrm{Be}$ in air sample filters. Be contamination is a serious issue at several DOE facilities, and rapid, effective techniques for air analysis would greatly enhance cleanup efforts at sites where Be contamination is known or suspected to occur. 


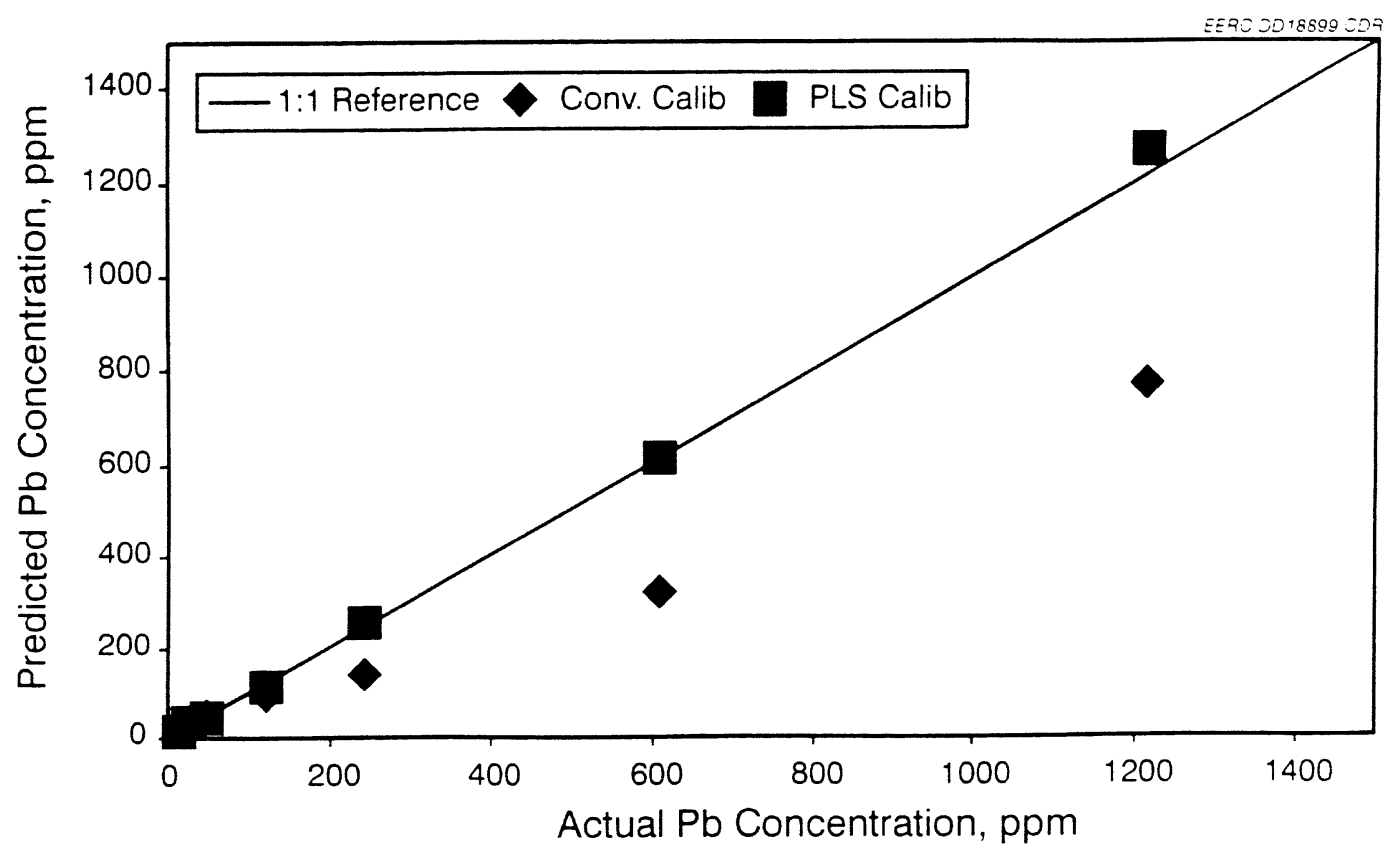

Comparison of Conventional and Improved Methods

for Prediction of Pb Concentration in Soil by LIBS/SparkID 


\section{Task 14 - Bubbleless Gas-Transfer Technology}

\section{Industry Partner}

Baumgartner Environics Incorporated

\section{Duration of Task}

December 1996 - December 1997

\section{Technology Integration Team}

EERC Task Manager

Project Staff

Student
John R. Gallagher Marc D. Kurz

Edwin S. Olson

Alisa M. Wenker

\section{Background and Objectives}

Widespread contamination of the subsurface, especially groundwater, has resulted in the need to develop cost-effective technologies for site remediation. Biological methods of remediation are often the least expensive, but they require that nutrients and electron acceptors, and sometimes electron donors, be supplied. Often these electron acceptors and donors are gaseous compounds such as oxygen, methane, or hydrogen. The addition of gases to liquids has typically been performed by sparging, which tends to waste gases, volatilize contaminants, and potentially plug the aquifer. The bubbleless gas transfer technology uses a module constructed of a bundle of hydrophobic membrane tubules set within a pipe to saturate the water flowing through it with the desired gas. One important application of this technology being explored is in the treatment of highly chlorinated solvents.

Tetrachloroethylene (also known as perchloroethylene, or PCE) has been widely used as an industrial solvent and degreaser and for dry cleaning. PCE is heavier than water, poorly soluble in water, and recalcitrant to biological activity. In fact, the only rapid method to remediate PCE is through a process known as reductive dehalogenation. Reductive dehalogenation is a microbially mediated process where PCE or similar compounds are used as the electron acceptors and are subsequently dehalogenated. Therefore, to encourage active reductive dechlorination, the contaminated site must be supplied with an excess of a suitable electron donor. Hydrogen gas has been shown to be the preferred electron donor for this process. However, the low solubility and explosive nature of this gas has prevented its use. The bubbleless gas transfer technology has the potential to supply appropriate quantities of hydrogen without wastage and in a safe manner.

Laboratory aquifer simulators were used to demonstrate the use of hydrogen for reductive dehalogenation of PCE in a contaminated aquifer.

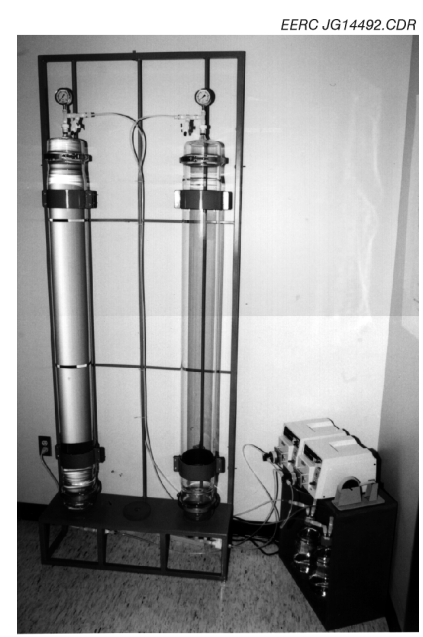

The Two Aquifer Test Columns, Constructed of Borosilicate Glass with Teflon ${ }^{\mathrm{TM}}$ Fittings Being Leak-Tested Before Filling with Aquifer Material

\section{Results}

Two simulated aquifer units were constructed. These units are borosilicate glass columns measuring $1.75 \mathrm{~m}$ by $14 \mathrm{~cm}$ in diameter. Because PCE is volatile and a strong solvent, the columns, piping, and fittings were all of Teflon ${ }^{\mathrm{TM}}$, glass, and similar resistant materials. Each of the columns was filled with a sandy loam aquifer material that was contaminated with PCE. Simulated groundwater was pumped through the columns, each in an independent loop. When the concentration of PCE was found to be in equilibrium between the sediment and the water phases, hydrogen gas was introduced into one column. The other 
column served as the untreated control.

Early data confirmed that PCE at concentrations above $10 \mathrm{mg} / \mathrm{L}$ was toxic to reductive dechlorinating microbes. Later studies conducted in a flow-through mode at a mean PCE concentration of $1400 \mathrm{ppb}$ showed reductions in the simulator to about $840 \mathrm{ppb}$, for a total $570 \mathrm{ppb}$ removed in the simulator. This represents a significant improvement over what might be expected through natural attenuation alone (no additions) and shows that exogenously supplied hydrogen can stimulate the in situ removal of PCE.

\section{EM Application}

PCE and related chlorinated solvents are the most common types of contaminant found in the groundwater and are common at DOE weapons complex sites. The bubbleless gas transfer technology offers the potential for an inexpensive, fast, and effective means to remediate such contaminants. 


\section{Task 15 - Remediation of Organically Contaminated Soils Using Hot/Liquid (Subcritical) Water}

\section{Industry Partners \\ U.S. Department of Energy National Energy \\ Technology Laboratory, Morgantown \\ Western Environmental Services \& Technology Inc.}

\section{Duration of Task}

December 1996 - June 2001

\section{Technology Integration Team}

EERC Task Manager

Project Staff

Steven B. Hawthorne

Arnaud J. Lagadec

David J. Miller

\section{Background and Objectives}

Advanced on-site methods are needed to address remediation needs for high explosives (HE) and other organic contaminants that occur in soils at DOE sites. The EERC has obtained approval from the U.S. Patent Office on a patent covering the use of subcritical water for a variety of extraction processes, and additional applications covering the degradation of $\mathrm{HE}$ compounds were submitted in the fall of 1999. Labscale investigations at the EERC have demonstrated that simply controlling temperature allows both polar and nonpolar semivolatile and volatile organics to be extracted using only pure water and have clearly demonstrated the potential for using subcritical water as a remediation fluid. Personnel at the EERC were the first to conceive of and develop the use of subcritical water (hot water under enough pressure to maintain the liquid state, not supercritical water) as an efficient extraction medium for solids and semisolids. The technique was initially developed as an analytical tool for projects for commercial and government sponsors.

The objective of this task was to demonstrate the use of hot/liquid water for the safe, efficient, environmentally sound remediation of organic contaminants, particularly HE, for application to DOE site needs.

\section{Results}

During 1997, an 8-liter pilot-scale system was constructed, and an initial demonstration with a PAHcontaminated soil was successfully completed. The only problem encountered was the plugging of the extractor unit by small (micron-sized) soil particles and by expanded clays. During 1998, comparisons with other technologies including bioremediation and supercritical carbon dioxide were made, and of the three processes, only subcritical water successfully removed the PAHs from the contaminated soils. The types of pollutants on contaminated soils were expanded to include more polar organics (e.g., pesticides and HE present as soil contaminants at many DOE sites. The reactor-plugging problem was solved, and successful laboratory- and pilot-scale removals of pesticides (alachlor, metolachlor, pendimethalin, trifluralin, and atrazine) were completed. In 1999, laboratory-scale removals of HMX (cyclotetramethylene tetranitramine), RDX (cyclotrimethylene trinitramine), and TNT $(2,4,6-$ trinitrotoluene) on spiked soils were optimized, and the optimization of real (field-contaminated) soils was completed. An evaluation of both degradation (static extraction) and extraction (flowing extraction) of TNT and other HE was also completed.

Pilot-scale (8-liter) extractions of HEcontaminated soil were also completed in 1999, which demonstrated complete ( $>99 \%$ ) destruction of the explosives with no detectable toxic by-products. The results to date have been used to perform initial engineering cost analysis of a commercial-scale system. Cost estimates vary from about $\$ 100$ to $\$ 300 /$ ton, depending on the modeling approach used. However, when comparisons are done on an equal basis with other technologies proposed for HEcontaminated soils, subcritical water is consistently one of the least expensive alternatives.

During 2000, the pilot-scale system was optimized for static (no pumping necessary) operation. The unit is fully contained on a $6 \times 10$-ft trailer except for a source of electrical power. This portable unit 


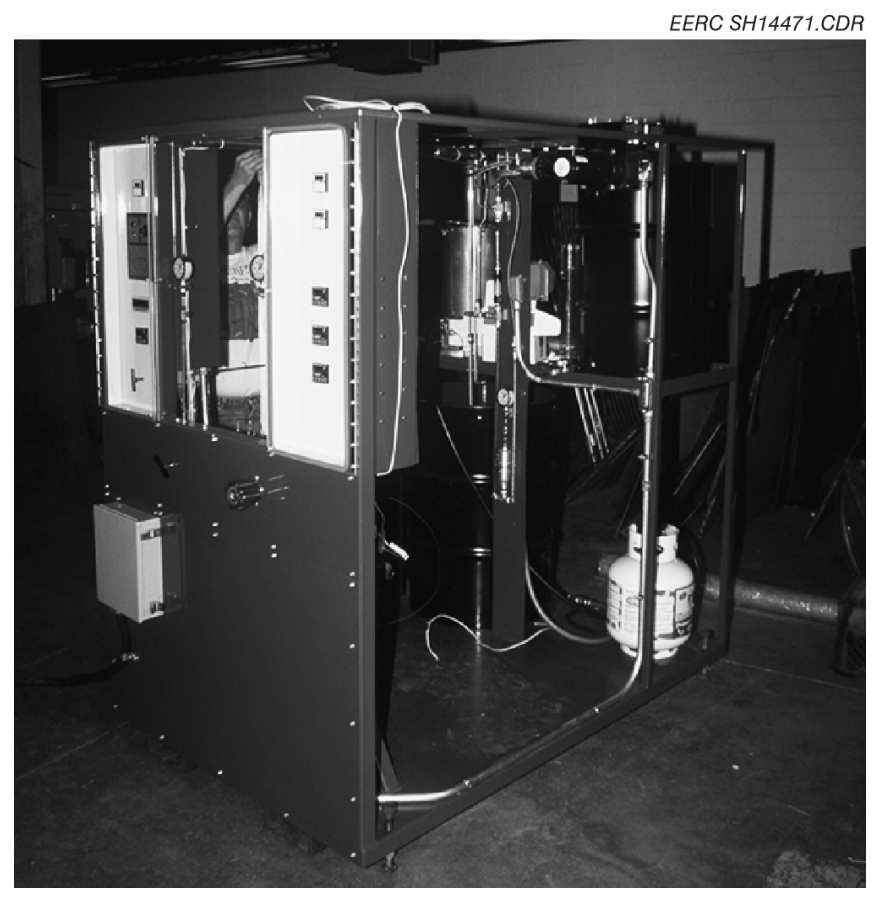

Portable Pilot-Scale (8-liter) Subcritical Water Remediation Unit

was used to remediate soil from Los Alamos under field conditions at the EERC facility. During this demonstration, RDX and HMX were reduced to nondectable levels in both soil and process water. Peter Gram (Information Technologies site manager for HE-contaminated soils at Los Alamos) witnessed the test. A paper describing the successful pilot-scale degradation of TNT-, RDX-, and HMX-contaminated soil was accepted and published by Environmental Science and Technology.

\section{EM Application}

Surface soils at DOE sites are contaminated with HE up to $>20 \mathrm{wt} \%$. Waste volumes are currently unknown, but are greater than 2000 cubic yards. At present, incineration requires shipment to an out-ofstate facility, with an estimated cost of $\$ 1000$ per cubic yard for incineration and $>\$ 10,000$ per cubic yard for shipment costs. This on-site technology can reduce costs and address environmental concerns over remediation of $\mathrm{HE}$ and other organic compounds at DOE sites. 


\section{Task 16 - Preparation of Sampling/Analysis and Availability Assurance Plans for the Vortec Vitrification Demonstration Plant}

\begin{tabular}{|lr|}
\hline Industry Partner & \\
Vortec Corporation & \\
Duration of Task & \\
December 1996 - April 1997 & \\
Technology Integration Team & \\
EERC Task Manager & John P. Hurley \\
Principal Investigator & Dennis L. Laudal \\
Project Staff & Carolyn M. Lillemoen \\
& Sumitra R. Ness \\
& Daniel J. Stepan \\
\hline
\end{tabular}

Background and Objectives

The Vortec Cyclone Melting System $\left(\mathrm{CMS}^{\circledR}\right)$ facility, proposed for the DOE Paducah Gaseous Diffusion Plant, was designed to treat soil contaminated with low levels of heavy metals and radioactive elements as well as organic waste. The facility was never constructed. The primary components of the proposed Vortec $\mathrm{CMS}^{\circledR}$ included a counter-rotating vortex (CRV) reactor and cyclone melter. In the $\mathrm{CMS}^{\circledR}$ process, granular glass-forming ingredients and other feedstocks are introduced in the CRV reactor where the intense CRV mixing allows the mixture to achieve a stable reaction and rapid heating of the feedstock materials. Organic contaminants in the feedstock are effectively oxidized, and the inert inorganic solids are melted.

The EERC was contracted to help develop sampling and analysis plans and to possibly conduct the sampling at the proposed facility.

During the initial phases of start-up and the first months of stable operation, sampling of gas, water, and solid materials is necessary to provide shakedown data for use in the development of standard operating procedures, to meet permitting requirements, and to provide mass balance data for compounds of interest.

\section{Results}

To ensure that the costs of sampling and analysis were contained, Vortec and DOE NETL determined that the primary focus of the sampling activities would be on meeting the permitting requirements of the state of Kentucky. Sampling would have been limited to the feedstocks entering the system and the glass, flue gas, and water leaving the system. To limit the number of samples that must be collected, it is assumed that the feed stream composition would have been constant over periods of at least 1 week. Data analysis should provide limited information that can be used to refine operating procedures and produce rudimentary mass balances. Additional sampling is not planned for support of these activities.

A two-stage demonstration plan for the $\mathrm{CMS}^{\circledR}$ was developed. The first stage involves shakedown. During this period, each part of the system would have been tested and brought on-line until the entire system is operational. Shakedown would have taken approximately 3 months. During the final 3 weeks of shakedown, the CRV would have been brought on-line and clean feedstock would have been processed. The EERC would have begun sampling during this last stage of the shakedown.

Following shakedown, the facility would have been operated at steady-state conditions for a total of 30 days. Low-level radioactive soils, RCRA (Resource Conservation and Recovery Act) wastes, and PCBcontaminated materials would have been processed. Initial sampling would have been performed in a way that ensured emission permit requirements were met. Additional sampling might have been required to aid in refining operations and in determining mass balances for individual species; sampling to support this work would have been optional.

The EERC would have collected samples of the feedstocks, vitrified product, and liquid waste streams as well as flue gas from three locations (for permitting 
purposes) and at a fourth optional location. Permits do not require speciation of the materials in the effluents; rather, they require opacity, total radioactivity, total particulate, and total $\mathrm{HCl}$ emissions for the flue gases and total radioactivity in the water and solid products. Should future testing to support operations or mass balances have been required, additional information on the analyses of some species of interest was included, e.g., heavy metals (RCRA and possibly $\mathrm{Cu}$ and $\mathrm{Ni})$, radionuclides $\left(\mathrm{Th}^{230}, \mathrm{U}^{235}, \mathrm{Tc}^{99}, \mathrm{Cs}^{137}\right.$, and $\mathrm{Pu}^{239}$ ), and dioxins/furans.

The sampling team would have followed health and safety protocols established by Vortec, would have successfully completed the 40-hour training for Hazardous Waste Operations and Emergency Response (29 CFR 1910.120), and would have fulfilled the requirements of EERC Standard Practice No. 303 - Personal Protective Equipment, No. 327 - Respiratory Protection, and No. 355 - Medical Surveillance Program.

Standard methods would have been used to sample the flue gas to assure that the plant emissions satisfy permitting requirements. Particulate matter would have been measured by using EPA Method 5 (transverse flue gas measurements will be made using EPA Methods 1 through 4). EPA Method 26A would have been used to measure $\mathrm{HCl}$.

Optional sampling to provide data for increasing plant efficiency and information on elemental mass balances would have included EPA Method 23 for dioxins/furans, EPA Method 29 for heavy metals, and filters from Methods 1-4 and solutions from Methods 2 and 4 to measure radionuclides.

For permitting purposes, samples from the feed preparation and blending facilities, soda ash and limestone silos, and outlet stack would have been collected.

The CRV exit gas stream prior to the wet ESP might have been collected during optional operations and mass balance sampling.

When optional speciation analyses are performed, appropriate analytical techniques would have been used as part of to a strict Quality Assurance (QA) plan. The QA plan would have ensured that Vortec and DOE were provided with meaningful data of defensible quality. Compatibility with sampling methods would have been considered when the appropriate analytical techniques are selected. Close communication between the sampling team and the analytical personnel would have ensured quality data by preserving sample integrity for all sampling and analytical activities. This would have been facilitated by following a detailed chain-of-custody protocol.

\section{EM Application}

Vitrification is one of the preferred remediation options for the radioactively contaminated soils found at the DOE weapons complex sites. The EERC's input on this project would have aided in the facility permitting process. 


\section{Task 17 - Use of Acoustic Energy and Humic Acids to Mobilize DNAPLs in the Subsurface}

\begin{tabular}{|lr|}
\hline Industry Partner & \\
Weiss Associates & \\
Duration of Task & \\
January 1997 - February 1999 & \\
Technology Integration Team & \\
EERC Task Manager & Edwin S. Olson \\
Principal Investigator & Marc D. Kurz \\
Project Staff & John R. Gallagher \\
\hline
\end{tabular}

\section{Background and Objectives}

Contamination of the subsurface by dense, nonaqueous-phase liquids (DNAPLs) is common throughout the United States, especially at DOE and DOD sites. These compounds are difficult to remove since they are not very soluble and tend to stay in pools or sorb strongly to aquifer materials because of their cohesiveness and nonpolar nature. Weiss Associates has found that acoustic energy can induce a two- to fourfold increase in hydraulic conductivity of low-permeability clays and an approximately $70 \%$ improvement in NAPL recovery compared to pumpand-treat-only conditions. Studies at the EERC have shown that humic acid surfactants possess properties similar to those of commercial surfactants, yet are not expensive, do not sorb to aquifer materials, do not exert a biochemical oxygen demand, and are nontoxic. The combination of acoustic energy and humic acids holds potential for faster, less-expensive remediation of subsurface DNAPL contamination when used to enhance pump-and-treat methods or in situ bioremediation. This task preliminarily evaluated the use of the acoustic energy-humic acid technology to enhance solubility and mobility of DNAPL

contaminants.

\section{Results}

A fifteen-test experimental matrix was performed to study the removal of trichloroethylene (TCE) from homogeneous Oklahoma 90-grit white quartz sand. Five different acoustic frequencies (none, $250 \mathrm{~Hz}$, $670 \mathrm{~Hz}$, pulsed $250 \mathrm{~Hz}$, and varied) were tested for each of three surfactant conditions (none, AOT [dioctyl sodium sulfosuccinate], and humate). The tests without acoustic energy and with either AOT or humate showed improvements over the baseline case (i.e., no surfactant, no acoustic energy addition) in removal of TCE of $87.1 \%$ and $67.8 \%$, respectively. Runs with acoustic energy and no surfactant showed improvements ranging from $23 \%$ to $85.5 \%$, with optimal improvements occurring when the acoustic frequency was varied. Tests using AOT showed average improvements of about $88 \%$ regardless of the acoustic treatment conditions. Tests with humate achieved the best results $(86.5 \%)$ when the acoustic frequency was varied. These results indicated that the use of humate coupled with varied-frequency acoustic excitation (see following figure) could greatly improve the removal of NAPLs such as TCE from aquifers at a low cost without adding the oxygen demand or toxicity seen with commercial surfactants.

\section{EM Application}

Several of the DOE weapons complex sites contain at least one area of NAPL subsurface contamination large enough for pump-and-treat operations to continue for many years. The acoustic energy-humic acid technology holds the potential to dramatically lower the time required for cleanup while improving the economics of such remediation. 
EERC MK16094.CDR

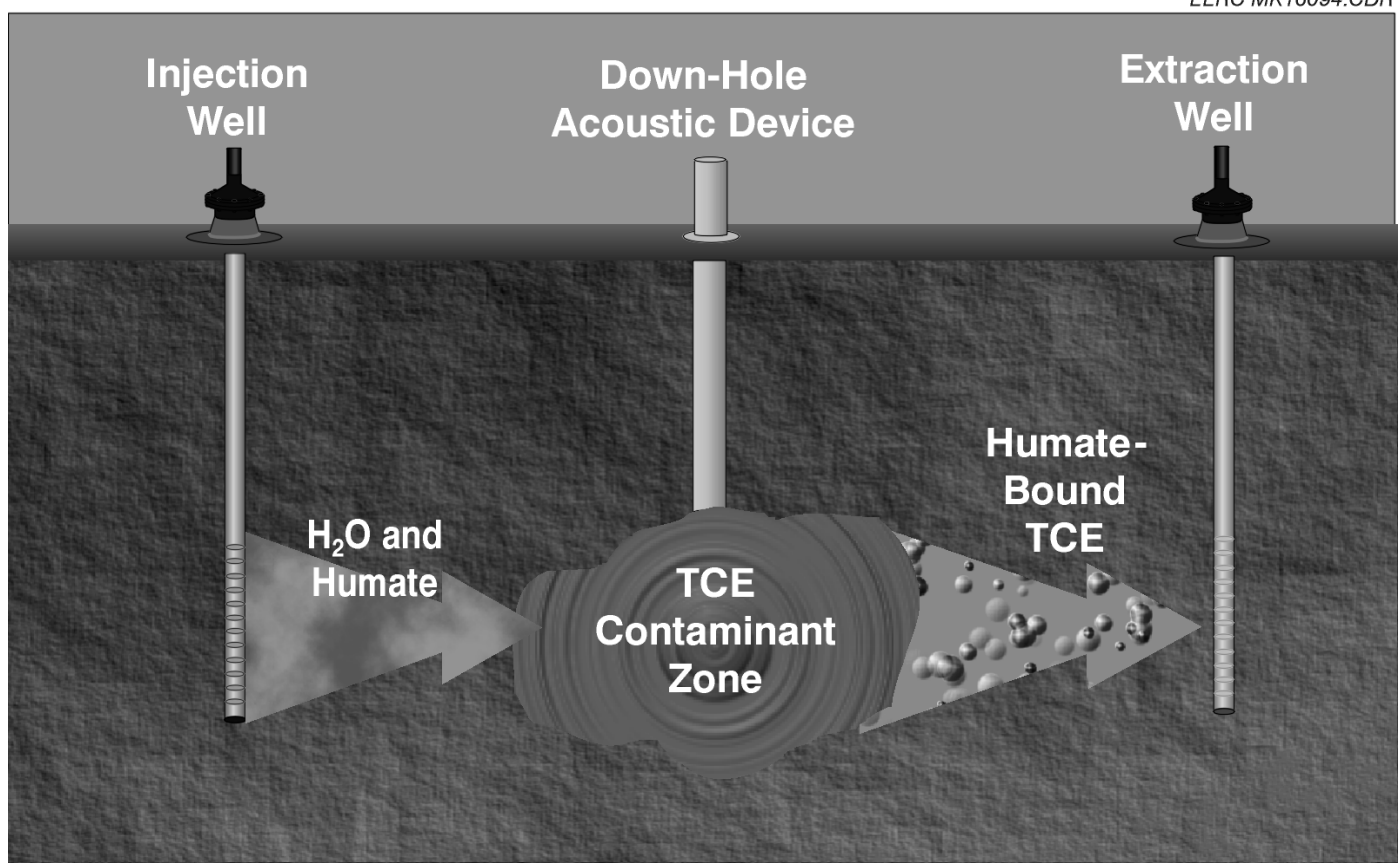

Pump-and-Treat System with Acoustic Excitation and Humate Application 


\section{Task 18 - Carbon Sorbent Optimization and Evaluation for High Levels of Mercury Contamination}

\begin{tabular}{l}
\hline Industry Partner \\
Mercury Recovery Services, Inc. \\
Duration of Task \\
January 1998 - December 1998 \\
Technology Integration Team \\
EERC Task Manager \\
\hline
\end{tabular}

\section{Background and Objectives}

Incineration is often the treatment of choice for mixed waste streams. When the waste contains mercury, the mercury vapor in the high-temperature offgas must be captured, stabilized, and disposed of. Current capture technologies are both expensive and subject to temperature limitations. The EERC has developed novel mercury sorbents that include surface-modified carbon as well as supported metal oxides. This sorbent development expertise was applied to a thermal desorption process developed by Mercury Recovery Services (MRS) of New Brighton, Pennsylvania, that removes mercury from soils and other solid matter. The mercury that is contained in the offgas from the drying and condensation stages is currently removed by a sulfided carbon sorbent that cannot be regenerated. Although MRS has commercially demonstrated its process, it is interested in developing and pursuing the commercialization of a new, less expensive mercury sorbent. The work performed during this project focused on evaluating the performance of the EERC sorbents under MRS process operating conditions.

\section{Results}

Previous sorbent work had shown that incorporation of nitrogen atoms into the carbon edge structures catalyzed the air oxidation of elemental mercury vapor, resulting in effective mercury capture. Surfacemodified carbons were prepared by impregnating activated carbon with a nitrogen heterocyclic precursor followed by recarbonization. Preliminary testing showed superior activity for the modified carbons.
Rates of mercury sorption were obtained as a function of temperature for several of the carbon and metal oxide sorbents. The catalytic carbon sorbents are highly active at ambient temperatures and become somewhat less active at higher temperatures. The metal oxide sorbents are very inactive at ambient temperatures and increase substantially in activity up to $200^{\circ} \mathrm{C}$. Thus the carbon sorbents were considered more appropriate for the MRS process that takes place at lower temperatures.

Regeneration of the carbon and metal oxide sorbents was demonstrated. A proprietary method was devised for regenerating the sorbents using a mild thermal treatment in a reactive gas composition to remove the mercury followed by a chemical reactivation of the sorbent surface. The regenerated sorbents exhibited higher activities than the original sorbent.

One of the new carbon sorbents was tested with very high mercury concentrations $\left(10,000 \mu \mathrm{g} / \mathrm{m}^{3}\right)$ at space velocity, temperatures, and moisture levels matching the MRS conditions in drying and retortingcondensation stages. No breakthrough was observed under the conditions representing the two stages.

\section{EM Application}

The effective mercury capture at higher offgas temperatures offered by the EERC-developed sorbents will be valuable during any of the mixed-waste incineration or vitrification tasks performed at the weapons complex sites. The regenerability of the sorbents will permit concentration of the mercury waste for more efficient storage, decontamination, or even recycle. 


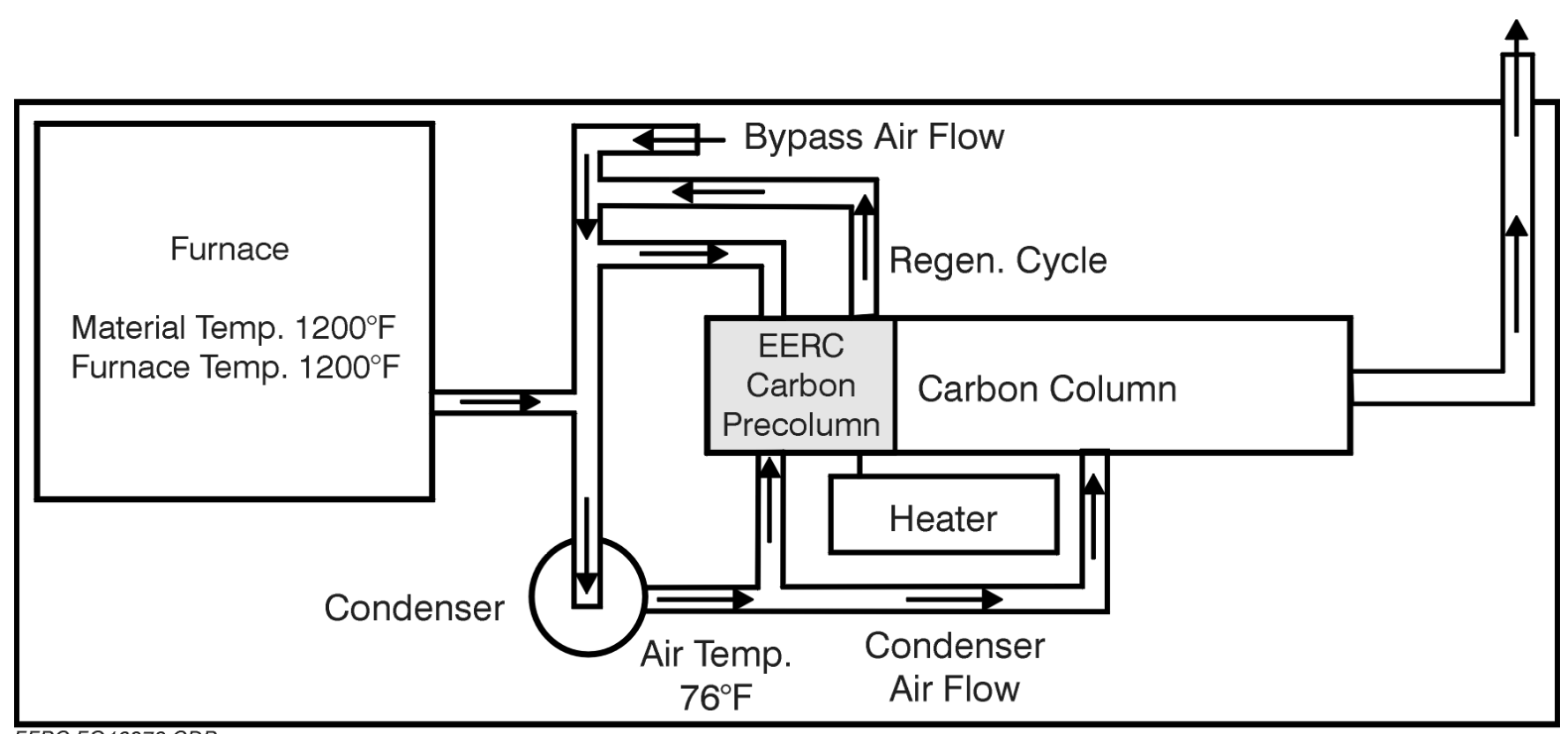

EERC EO16273.CDR

Schematic of Process with EERC Carbon Precolumn 


\section{Task 19 - Sampling, Analysis, and Vitrification Study for the ThermoChem Steam Reformer Treatment Technology}

\begin{tabular}{|lr|}
\hline Industry Partner & \\
ThermoChem, Inc. & \\
Duration of Task & \\
January 1998 - June 1999 & \\
Technology Integration Team & \\
EERC Task Manager & Donald P. McCollor \\
Project Staff & Bruce A. Dockter \\
& Carolyn M. Lillemoen \\
& Qi Sun \\
\hline
\end{tabular}

Background and Objectives

ThermoChem, Inc., of Columbia, Maryland, contracted with NETL to demonstrate the commercial capability of a steam-reforming process to treat lowlevel mixed waste (LLMW) from the DOE inventory. A process development unit was being tested to evaluate the technical and commercial capability of the system to destroy hazardous components with greater than $99.99 \%$ efficiency, isolate and stabilize radionuclides, and reduce the volume of low-level hazardous waste and LLMW. The evaluation tests employed cerium and monochlorobenzene as surrogates for uranium and PCBs. The EERC provided technical support to ThermoChem, Inc., by performing analyses of samples produced during surrogate testing with the reformer, determining temperature-viscosity profiles of the product ash to aid in vitrification analysis, and performing leaching tests on the vitrified ash.

\section{Results}

Samples from ThermoChem's steam reformer and gas cleanup system were analyzed for $\mathrm{Ce}, \mathrm{Cl}$, and $\mathrm{F}$ to determine the collection locations for each. In total, eighteen samples were analyzed. The first task was to develop suitable analysis techniques for the three elements of concern. Initial results using ICP spectroscopy showed low mass closures due to sample digestion procedures. XRF and ICP spectroscopy, coupled with a new digestion procedure, significantly improved mass closure. It was concluded that the $\mathrm{Ce}$ surrogate remains within the bed and high-efficiency particulate air (HEPA) filter system.
To determine the probable oxidation state and chemical species of Ce in the steam reformer as well as to determine the presence of volatile $\mathrm{Ce}$ compounds, equilibrium thermodynamic calculations were performed. The results indicated that gas- or liquid-phase cerium species are not predicted to occur. Cerium is predicted to be present only as solid $\mathrm{CeO}_{2}$ and $\mathrm{CeF}_{3}$ in the system. $\mathrm{CeO}_{2}$ is favored above a temperature of $887^{\circ} \mathrm{F}\left(475^{\circ} \mathrm{C}\right)$, below which both $\mathrm{CeO}_{2}$ and $\mathrm{CeF}_{3}$ can occur. Limited scanning electron microscopy morphology and microprobe analysis did not identify significant chlorine or fluorine in combination with $\mathrm{Ce}$, but rather $\mathrm{Ce}$ in combination with small amounts of $\mathrm{Si}, \mathrm{Ca}$, and $\mathrm{Mg}$. Therefore, the dominant $\mathrm{Ce}$ form is the oxide and is not converted to the fluoride at lower temperatures.

Viscosity tests were performed to determine the formulation that would produce a flowable slag at temperatures at or below $1200^{\circ} \mathrm{C}$ using minimal amounts of fluxing agents. The criteria of a flowable slag was taken to be a material with a viscosity of 250 poise or less. The results indicate that an optimal blend ratio of approximately $60-65 \mathrm{wt} \%$ ash, with $28 \mathrm{wt} \% \mathrm{Na}_{2} \mathrm{CO}_{3}$ and $9 \mathrm{wt} \% \mathrm{CaCO}_{3}$ as fluxing agents, results in a flowable slag with a viscosity of 250 poise or less in the $1000^{\circ}-1200^{\circ} \mathrm{C}$ temperature range.

Samples from two viscosity tests were used to evaluate the leaching potential of components from a matrix. These slags were spiked with $\mathrm{CeO}_{2}$ to provide a sufficient $\mathrm{Ce}$ concentration to detect any appreciable leaching. A series of leaching experiments, including an 18-hour test, a 1-week test, and a 2-week test, were performed. The leachate concentrations and calculated percentage of individual elements leached indicate very stable matrices, with the possible exception of the sodium component. No detectable levels of Ce were leached from the slags.

\section{EM Application}

This project supported ThermoChem's determination of the feasibility of using its steam reforming process to treat LLMW. The work performed provided 
important information as to the mass balance of the $\mathrm{Ce}$ surrogate in the system, optimal levels of fluxing agents for vitrification of the resulting ash, and evaluation of the leaching potential of the vitrified slag. These data increase the likelihood that ThermoChem's steam reforming process could be successfully applied to the LLMW found at virtually all DOE weapons complex sites.

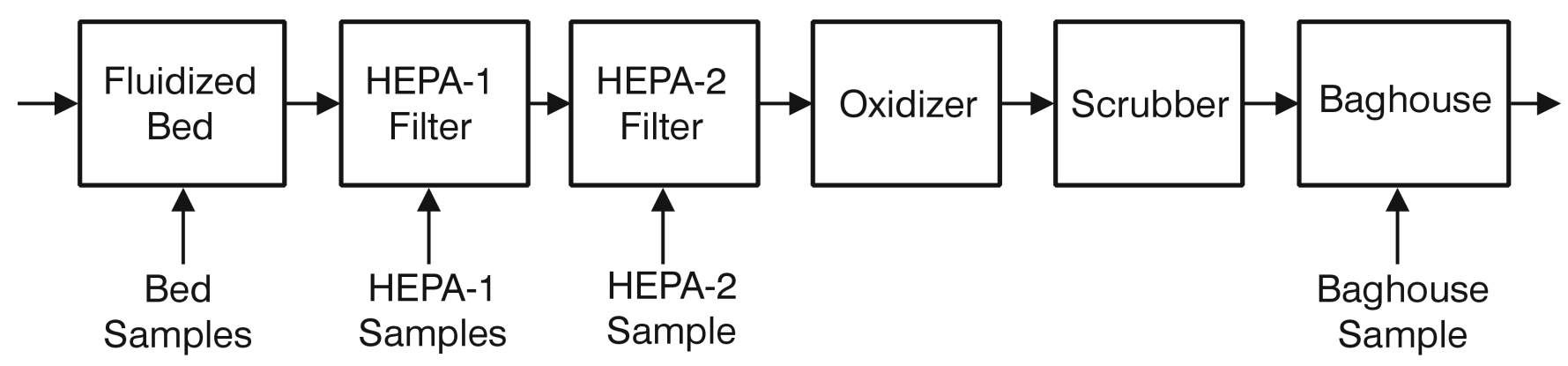

EERC DM15163.CDR

Sampling Locations for Steam Reforming Process 


\section{Task 20 - Prevention of Chloride Corrosion in High- Temperature Waste Treatment Systems}

\begin{tabular}{|lr|}
\hline Industry Partner & \\
GTS Duratek & \\
Duration of Task & \\
December 1997 - October 2000 & \\
Technology Integration Team & \\
EERC Task Manager & Ted R. Aulich \\
Project Staff & Ronald C. Timpe \\
& Ronald W. Kulas \\
\hline
\end{tabular}

\section{Background and Objectives}

GTS Duratek of Columbia, Maryland, is developing a vitrification facility as part of the River Protection Project at Hanford. However, sulfate in the tank wastes destined for the vitrification plant can damage the vitrifier electrode, and chloride in the wastes can damage vitrifier internals and components of the vitrifier emission control system. Removal of corrosives from tank wastes is difficult because the presence of up to 10-molar concentrations of sodium hydroxide along with significant levels of nitrate, nitrite, phosphate, chromate, and other anions (including complexed radionuclides) renders standard ion exchange, membrane filtration, and other separation technologies relatively ineffective. The EERC was charged with developing an economical process for removing corrosive chloride and sulfate from the vitrifier feedstocks.

\section{Results}

The EERC developed regenerable, flow-through, column-based processes for removal of corrosive chloride and sulfate from vitrifier feedstock. The processes employ chloride- and sulfate-specific ion exchange and were demonstrated to provide consistent $99 \%$ removal of chloride and sulfate from the tank waste simulants prepared by GTS Duratek.

The EERC processes employ commercially available cation-exchange resins that have been converted to anion exchangers specific for either sulfate or chloride. Sulfate- and chloride-specific resins are prepared by incorporation, under prescribed conditions, of zirconium and silver, respectively, onto active sites of a commercial cation-exchange resin. The use of specific conditions in the incorporation process is required to ensure maximum strength of the zirconium or silver attachment to the resin matrix. A preliminary estimate of the ion-exchange capacity of the sulfate-specific resin is about 2.4 milliequivalents per gram on a dry basis. In a series of "stir-and-filter" tests in which a single batch of sulfate-specific resin was used and regenerated eight times, sulfate removals of $99 \%$ were consistently achieved, and in all tests, regenerated resin was demonstrated to work as well as or better than new resin.

The ion-exchange processes were configured for performance in a column to demonstrate their economic viability in commercial-scale application. Treatment in the column configuration is achieved by slowly pumping tank waste upward through the resin bed. Since suspended and precipitated solids exist in real and simulated tank wastes, slowly pumped upflow is superior to gravity-driven downflow through the column because slow upflow can prevent deposition on the resin bed of suspended solids, many of which (in real tank wastes) would likely contain metals and radionuclides. Keeping suspended solids out of the resin bed also maximizes access to resin-active sites, minimizes clogging, and minimizes generation of secondary wastes.

Regeneration of sulfate-specific zirconiumincorporated resin in the column configuration is accomplished by slowly pumped upflow of a barium hydroxide solution, which removes sulfate from resinactive sites via precipitation of barium sulfate, leaving zirconium-active sites ready for another round of sulfate uptake. The column-configured process has been demonstrated to provide $99 \%$ sulfate removal and be $100 \%$ regenerable. A series of tests was performed in which a single batch of sulfate-specific ion-exchange resin was put through three use cycles, each of which comprised treatment of a fresh, nevertreated charge of GTS Duratek-prepared tank simulant, followed by resin-bed regeneration with barium hydroxide. Sulfate removal in each test was 
greater than $99 \%$.

Tests were performed to evaluate the specificity of the EERC sulfate removal process. High sulfate specificity is crucial to ensuring against "holdup" on the resin bed of negatively complexed radionuclide and metal species along with sulfate. Preliminary data indicate the occurrence of no holdup with chromium, cobalt, nickel, and magnesium and possible occurrence of holdup with aluminum, boron, and strontium. If the occurrence of metal holdup is definitively established, to minimize secondary waste generation, metals-contaminated resin at the end of its useful life span can undergo a final barium hydroxide wash for sulfate removal, then undergo an acid treatment identical to that prescribed for regeneration of commercial cation-exchange resins. This will displace the metals into solution and return the sulfatespecific anion-exchange resin to its original state as a cation exchanger. The sulfate-free solution containing displaced metals (and, possibly, radionuclides) can be disposed of via vitrification, and the sulfate-free resin can be disposed of via vitrification or another appropriate means.

\section{EM Application}

The process provides the basis for an economical method of treatment for many of the waste streams destined for vitrification at DOE sites. 


\section{Task 21 - Development of Systems Engineering Applications for the Deactivation and Decommissioning Activities}

\begin{tabular}{|ll|}
\hline Industry Partner & \\
None & \\
Duration of Task & \\
June 1998 - December 1998 & \\
Technology Integration Team & \\
EERC Task Manager & Erin M. O'Leary \\
Project Staff & Mark M. Musich \\
\hline
\end{tabular}

\section{Background and Objectives}

Over time, the focus of this task for the DOE

Deactivation and Decommissioning Focus Area (DDFA) changed from the development of an overall D\&D model to the development of smaller, more feasible tools to support D\&D operations across the EM complex.

\section{Results}

The purpose of this task was to assist the DDFA in its annual project planning and budgeting processes, principally through the collection and assay of EM data related to the DDFA and through the development of data analysis tools.

The initial focus of this task was the development of a paper model whose algorithms predicted the technology operating costs, primary and secondary waste volumes, and waste disposal costs associated with D\&D activities across the EM complex. To support the model, a database containing surplus facility and D\&D technology data was developed. The database currently contains over 1100 technologies and 15,000 facilities. Significant effort was expended to locate dependable supporting information within the EM complex, such as fixed and variable costs for technology operation, technology performance data, and surplus facility size, materials of construction, and types and levels of contamination. However, little facility information was available, and reliable technology information could only be found for systems evaluated in the DDFA Large Scale Demonstrations and Deployments.
The model was designed and submitted to a second party for inclusion with its proprietary user interface. However, budget and time constraints for the second party forced it to suspend indefinitely incorporation of the model.

Beginning in November 1998, this task changed its focus from development of the D\&D model to the development of smaller, more feasible tools to support DDFA operations. The database was transitioned to supporting DDFA activities such as the assessment of STCG (Site Technology Coordinating Group) Needs. The Needs, PBS (Project Baseline Summary) and Focus Area Work Package data and relationships obtained from various unintegrated EM databases and Web sites were incorporated into the D\&D database to facilitate improved and faster data analysis critical to DDFA operations.

The D\&D database was used to facilitate the matching of potential D\&D technologies to STCG Needs for the FY1999 and 2000 Needs Responses. For the FY99 Needs Response, over 136 Office of Science and Technology (OST)-funded D\&D technologies and over 130 Needs were coded through the preferred deployment technology (PDT) structure, originally developed under EM-40. For the FY00 Needs Response, 316 OST-funded or commercially available D\&D technologies and 198 Needs were similarly coded. The list of Needs-potential technology matches formed the basis for discussions between the DDFA technical teams and end users at the various EM sites. A final list of technologies that the sites planned to deploy, along with associated Work Packages, was entered into the Needs Management System by the EERC as part of the FY99 Needs Response process.

The EERC has continued to modify the PDT structure to reflect the growing scope of D\&D Needs and technology capabilities and to update the database with respect to technologies, Needs, and PBSs. The D\&D database has been updated to include over 1100 technologies and almost 200 Needs. 
To facilitate a more efficient and direct interaction between the DDFA technical teams and potential technology users at the EM sites, the EERC developed several on-line database tools. The first, called the D\&D Information System (DDIS), has a user interface that allows examination of the technology, Needs, PBS, and Work Package relationships. The DDIS transparently uses the PDT structure to provide technology and Needs matches. The DDIS was distributed on the NETL local area network (LAN) and has been updated several times in response to end-user recommendations.

The second tool, called the Needs Response Template, was developed to assist the FY2000 Needs Response process. The Needs Response Template is supported by data subsets of the D\&D database. The Response Template includes pertinent Needs statement data (e.g., priority ranking, Need description), OST and non-OST technology solutions for the Need (as mapped through the PDT structure), narrative response and additional comments, and similar Needs. The Needs Response Template was also placed on the NETL LAN and is being used for the FY00 Needs Response.

The EERC has also provided other systems engineering support such as the development of a methodology to prioritize the Needs for which the DDFA is tasked to provide technologies or technology solutions. This methodology relies on information related to the Needs, PBSs associated with the Needs, and the overall optimization of the D\&D Focus Area. The Needs Prioritization Methodology was used for the first time with the FY2000 Needs Response.

The overall D\&D database was continually updated and modified as new data were acquired related to technologies, Needs, PBSs, Work Packages, and facilities. In addition the database was used as a tool in a number of small D\&D analyses/exercises such as specific technology requests from EM site end users.

A significant amount of this task included day-today support for the DDFA in areas such as data review and packaging for use in documents such as the Annual Performance Plan.

\section{EM Application}

The on-line DDIS database and the information gathered and added to the overall D\&D focus area database will enable EM site managers to better select technologies for demonstration or deployment that will meet their sites' needs. 


\section{Task 22 - Pipe Explorer ${ }^{\mathrm{TM}}$ XRF Enhancement}

Industry Partner

Science \& Engineering Associates

Duration of Task

Not Funded

Technology Integration Team

EERC Task Manager

Ames A. Grisanti

Project Staff

Charlene R. Crocker

Carolyn M. Lillemoen

\section{Background and Objectives}

The Science and Engineering Associates (SEA) Pipe Explorer ${ }^{\mathrm{TM}}$ system has been successfully deployed at various DOE facilities. To provide in-pipe mercury assay, an XRF detector will be added to the suite of detectors available for the system. The EERC will support SEA's development work by preparing calibration samples for XRF through laboratory simulation of field sample matrices and by participation in the field deployment work at the Y-12 Plant at the Oak Ridge National Laboratory.

\section{Results}

The project was canceled because commercial sponsor funding was discontinued. 


\section{Task 23 - Thermodynamic Modeling of Volatile Hazardous Metal Behavior in the Vortec Vitrification System}

\begin{tabular}{|ll|}
\hline Industry Partner & \\
Vortec Corporation & \\
Duration of Task & \\
January 1999 - December 1999 & \\
Technology Integration Team & \\
EERC Task Manager & John P. Hurley \\
Project Staff & Jan W. Nowok \\
\hline
\end{tabular}

Background and Objectives

Experience at the EERC with low-grade fuel-fired thermal energy systems has shown that portions of the inorganic material inherent in the fuel vaporize during heating. Vaporization can occur either through physical vaporization or through chemical reactions, especially in the presence of sulfur, halides, or water vapor. It is likely that in a waste melter, vaporization also occurs, not just from a solid or liquid fuel, but from the wastes themselves. Downstream of a melter, the vapor species can condense, possibly forming fine particulates or even massive deposits that are highly concentrated in specific elements. In proprietary EERC work, element enrichment factors of up to 50,000 times have been measured in massive coal ash deposits as compared to the fuel. Such enrichments of radioactive or RCRA elements in a melter could produce hazardous deposits at specific sites within the system. Also, submicron particulates may pass through the scrubber and could more rapidly clog downstream HEPA filters. However, knowledge of the vaporization and condensation behavior of the hazardous elements can be used to propose simple methods to prevent such problems from occurring.

The primary activity of Task 23 was to perform thermochemical equilibrium computer modeling to provide a background of information on the possible vaporization and condensation behavior of radionuclides and RCRA elements in a propane-air flame. Two temperatures in or near the flame were modeled, $2000^{\circ}$ and $2800^{\circ} \mathrm{F}$, in a broad range of oxygen-propane ratios (1.5-7.0). The work was done in cooperation with the Vortec Corporation of
Collegeville, Pennsylvania. Vortec had proposed to build a demonstration fossil energy-fired vitrification system at the Paducah Gaseous Diffusion Plant near Paducah, Kentucky.

The goal of the activity was to use the results of the computer modeling to help predict the potential for operational difficulties in gas-fired waste melters. By modeling the vaporization/condensation behavior of hazardous metals within the melter, we were able to determine and quantify factors affecting the development of some of these operational issues. Once this information was obtained, simple methods to prevent their occurrence were delineated. They included on-line control with sootblowers, installation of access panels at specific locations to allow hot offline deposit removal, or minimizing vaporization by appropriate selection of feedstocks or blending scenarios or operating the burner in fuel-rich or leanmodes.

Version 3.0 of the Facility for the Analysis of Chemical Thermodynamics, or FACT code, was used for the modeling. It was developed at the Ecole Polytechnique de Montréal. The advantage of the FACT model over other codes is the amount of species in the thermochemical database (over 7000), the number of elements and species that can participate in complex reactions, and the ability to optimize solutions representing nonideal mixing in complex melts.

The model was used to evaluate the partial pressures of major components in a flame derived from $\mathrm{CN}, \mathrm{F}, \mathrm{Cl}, \mathrm{S}, \mathrm{OH}, \mathrm{U}, \mathrm{Pu}, \mathrm{Th}, \mathrm{Np}, \mathrm{Tc}$, and Cs. The maximum concentrations expected in the possible waste materials to be vitrified by Vortec during a 30day test period early in the operation of the system were used for the calculations. In the flame, stable equilibria are seldom reached; however, an equilibrium analysis can give insight into possible chemical reactions that may occur under given conditions of composition, temperature, and pressure. It was assumed that the vapor-phase products formed 
at high temperatures are transported by the flue gas to lower temperatures where they can condense. It is important to realize, however, that uncertainties will occur in the prediction of vaporization and condensation behavior if components that may form during operation of the Vortec system are not included in the FACT code database because of lack of thermodynamic data. The calculations were performed in a series of steps in order to diminish the effect of competing system conditions.

\section{Results}

The thermochemical equilibrium calculations indicate that at the temperature of a propane-air flame, some volatilization of uranium, plutonium, technetium, and cesium would occur. The expected concentrations of plutonium, technetium, and cesium in the flame would be very low because of the small maximum concentration of these elements in the projected feed materials for the first 30-day test. The quantities volatilized can generally be decreased by operating the flame in a fuel-rich mode, although this will lead to greater carbon monoxide production, which may be more objectionable unless reburned. The concentrations of chlorine and fluorine, at least at the maximum levels in the proposed Vortec feed, are not projected to greatly influence the vaporization rates. Therefore, blending to reduce the concentrations of those elements would most likely not be effective in reducing metal vaporization. Most of the elements vaporized condense by the time the gas cools to $2000^{\circ} \mathrm{F}$. These elements would condense either on surfaces near the front of the heat recuperator or on entrained particulates or homogeneously as relatively pure submicron particles. Cesium would be expected to condense at the lower temperatures near the rear of the recuperator, although the expected maximum concentration in the Vortec feed material is extremely low so it should be greatly diluted by other particulates. The elements that condense on other entrained particles would form enriched surface coatings. Particles larger than $10 \mu \mathrm{m}$ or so would be collected in the scrubber. Smaller particles, especially the submicron particles formed from homogeneous nucleation, should be largely collected in the HEPA filter.

Deposits formed in the heat recuperator could normally be handled via sootblowing. To reduce handling problems, we suggested that the recuperator be oriented vertically so that the deposits blown off of the heat exchanger fall directly into the molten glass. The large size of the deposits should help to reduce the rate of revaporization, allowing the volatile elements to be removed with the glass. The volatile elements that do not deposit on system surfaces would be concentrated in the smaller particles. Therefore, the HEPA ash would be greatly enriched in these elements. If the HEPA filter is itself sent to a melter, the elements may revaporize and multiply the problems related to metal vaporization significantly. Therefore, the HEPA filters should be disposed of without high-temperature processing. Also, to reduce the formation of these very small particles, it is helpful to include in the feed larger particles to act as condensation nuclei that can then be collected in the scrubber. This could be accomplished by using feed materials with a fraction consisting of particles small enough that they will not be collected in the cyclone in the melter, but large enough that they will easily be collected by the scrubber. This is one advantage that firing bituminous coal has over gas firing; it provides a source of ash particles of the right size range to serve as nucleation sites, but large enough (depending on the coal) so that they can usually be collected efficiently in the scrubber system.

\section{EM Application}

The computer modeling of chemical equilibria was carried out specifically in support of the Vortec demonstration vitrification system intended for the Paducah Gaseous Diffusion Plant in Kentucky. However, the information developed during this project is of use to all operators of vitrification plants handling waste streams containing possible volatile hazardous metals. 


\section{Task 24 - Development of an In Situ Instrument for Measuring Mercury in a Gas Stream}

\begin{tabular}{|ll|}
\hline Industry Partner & \\
Sensor Research and Development Corporation \\
Duration of Task & \\
January 1999 - Spring 2001 & \\
Technology Integration Team & \\
EERC Task Manager & Dennis L. Laudal \\
Project Staff & Grant E. Dunham \\
\hline
\end{tabular}

\section{Background and Objectives}

During the last several years, DOE has been developing thermal and incineration processes for treating hazardous mixed wastes. These mixed wastes often contain mercury, which is released into the atmosphere during the incineration process. EPA, as well as many states, clearly views mercury emissions from incinerators and combustion systems as a potential human health problem. Continuous emission monitors (CEMs) are a very attractive option for measuring mercury emissions because the data are in near-real time, allowing them to be used as feedback control for mercury control strategies. Also, a properly designed analyzer would require minimal operator input.

For the past several years, Sensor Research and Development Corporation (SRD) has been developing a very novel technique based on surface acoustic wave (SAW) technology that has the potential to be the basis for a simple, portable, and very-low-cost mercury CEM. Although the instrument would be low cost, it would still have the potential to provide reasonable detection limits for mercury. The EERC helped SRD test the instrument and guided SRD toward commercialization. The overall goal of the project (for both SRD and the EERC) was to provide an inexpensive, reliable analyzer that can measure total mercury under a variety of flue gas conditions.

\section{Results}

The SAW sensor consistently detected elemental mercury concentrations under continuous sampling conditions with a detection limit of less than
$1 \mu \mathrm{g} / \mathrm{dscm}$ in dry nitrogen. Under transient spike conditions, the detection limit was larger but still less than $10 \mu \mathrm{g} / \mathrm{dscm}$. Under both operating regimes, results were obtained with repeatability of better than $5 \%$ during exposure times of many hours. These results compared very well to the initial goal of detection at less than $25 \mu \mathrm{g} / \mathrm{dscm}$. The laboratory experiments clearly demonstrated the sensitivity and repeatability of the technique.

In the early phase of the project, high concentrations of acid gases such as $\mathrm{HCl}$ were found to have a severe effect on sensor response. These problems were eliminated by using the SRD instrument in conjunction with sampling and gaspreconditioning systems developed at the EERC. Because these systems dealt with the interferences and converted the mercury in the sample to the elemental phase, the SAW device could measure elemental mercury at room temperature. The sensor was then modified to operate under these conditions.

Tests were conducted under spiking conditions using a full suite of flue gases, including $\mathrm{SO}_{2}, \mathrm{HCl}$, and $\mathrm{NO} / \mathrm{NO}_{2}$. The first of these tests evaluated the use of the preconcentration system to increase mercury sensitivity. It was found that by concentrating the mercury on a gold trap and then rapidly releasing the mercury through heating, the preconcentration unit greatly enhanced instrument sensitivity. The test results showed excellent agreement with the Semtech Hg 2000 mercury CEM, and no poisoning effects were observed.

Next, the instrument was operated in the continuous mode while equipped with the preconditioning/pretreatment system. In contrast to the success of the tests run in the spiking mode, the continuous-mode tests were unsuccessful. Immediately upon introduction of the sample, the instrument showed contamination effects. Apparently when operated in the continuous mode, the inlet gas overwhelmed the preconditioning system. 


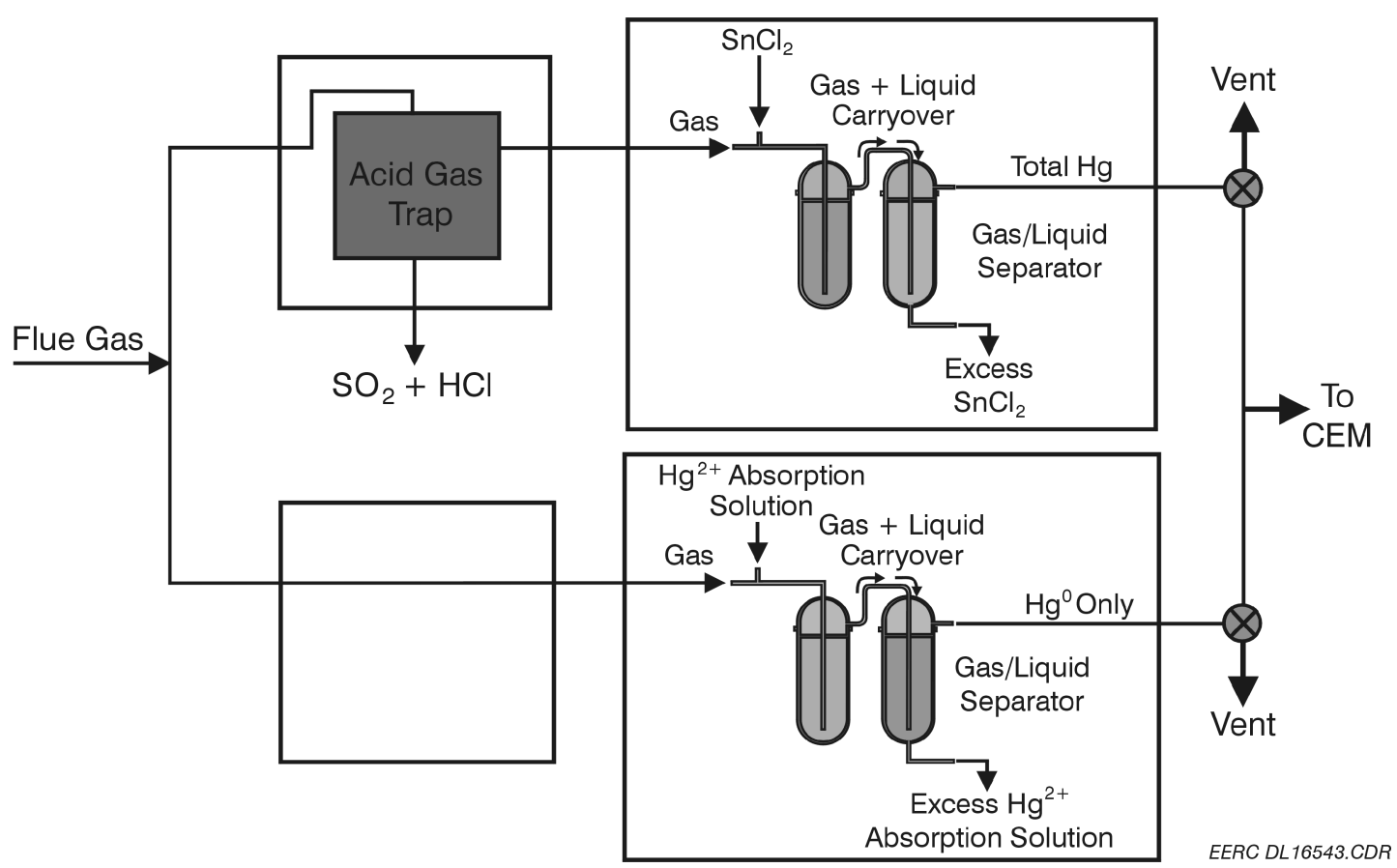

Flue Gas Preconditioning System

Although the SRD sensor system has met all the contractual developmental milestones, it is clear that further testing is necessary to quantify the conditions that lead to impaired sensor response and then to determine options from available filtration technology.

\section{EM Application}

A versatile CEM will be required at any of the DOE sites at which thermal treatment of hazardous mixed wastes is employed. For example, mercury CEMs are acutely needed at the Oak Ridge facility. Although several vendors are attempting to develop mercury CEMs for this type of application, none is currently in use. 


\section{Task 25 - Processing Contaminated Plant Residues}

\section{Industry Partner}

Phytokinetics, Inc.

Duration of Task

October 1999 - December 2000

Technology Integration Team

EERC Task Manager

Project Staff

Melanie D. Hetland

Daniel J. Daly

\section{Background and Objectives}

Phytoremediation is not a new technology, but to date the problem of postremediation treatment of the plants has not been addressed on a large scale. This becomes important when the contaminants are not evapotranspired or converted to nonhazardous compounds by the plants. The current baseline technology for treating plants that have taken up heavy metals such as mercury, chromium, or lead is to harvest, dry, and store them, meaning that some type of treatment of the plant residue is necessary to prevent recontamination of the environment. The EERC performed a preliminary assessment of three postphytoremediation treatments: cofiring with coal, liquid extraction, and composting.

\section{Results}

Phytokinetics arranged for approximately $2 \mathrm{~kg}$ of dried, varied plant material including small sunflowers (heads, stalks, leaves, and roots), grasses, and leaves to be obtained for testing from Phytotech Division of Edenspace Systems Corporation. The biomass had been used to phytoremediate a lead-contaminated site and contained nominally $1 \mathrm{wt} \%$ lead on a dry basis. It was prepared for the various processing tests (i.e., cofiring with coal, liquid extraction, and composting) by reducing it to less than $0.16 \mathrm{~cm}$ in diameter in a laboratory mill.

Leaching tests performed on the biomass showed that lead leached at significantly higher levels than the current RCRA limit of $5 \mathrm{mg} / \mathrm{L}$, suggesting that untreated biomass might present a significant environmental hazard if disposed of in an unstabilized manner and that some type of processing is warranted.
For the cofiring test, the biomass was combined with -200-mesh subbituminous coal in a 20:80 weight ratio of biomass to coal. The test was performed in the EERC's conversion and environmental process simulator. Flue gas was sampled, and ash was quantitatively collected from the bottom of the combustor, the convective pass, the heat exchanger, the baghouse, and the flue gas stream. Analysis of these samples enabled the reduction of leadcontaminated mass during the cofiring test to be calculated at between $90.8 \%$ and $93.6 \%$. The lead contained in the biomass remained in the ash, apparently concentrating in the smaller particulate. Cofiring contaminated plant material should probably be employed only at combustors possessing adequate particulate control devices. It should also be noted that the lead-containing ash might not be suitable for typical ash utilization activities and could require disposal at a hazardous waste landfill.

The volume reduction of lead-contaminated material was also evaluated during chelation extraction tests. The two chelating agents chosen for use during this project were $\mathrm{N}$-(2-acetamido) iminodiacetic acid and (ethylenedinitrilo)-tetraacetic acid disodium salt (EDTA). Biomass was contacted with the chelating agents, filtered, and the process repeated for a total of three batch extractions. The analyses of the three resultant liquids and the lead concentrations of recovered biomass solids were used to calculate a mass balance to determine extraction efficiency. The results showed that it was possible to extract more than $98 \%$ of the lead during only two extractions using EDTA and that more than $99 \%$ of the lead could be removed in three extractions.

Composting tests were performed by wetting the biomass, placing it into small chambers at a constant temperature, and monitoring the evolved $\mathrm{CO}_{2}$ for an incubation period of 62 days. Neat plant material, plant material with borosilicate Rashig rings added to improve permeability, and plant material with Rashig rings and added inocula were all composted. The concentrations of $\mathrm{CO}_{2}$ and $\mathrm{O}_{2}$ were measured, the data plotted cumulatively, and lag times, biodegradation 
rate, and extent of biodegradation estimated from the plots. The plots indicated that compost activity would have continued with additional incubation, although probably at a very low rate and that the lag periods were slightly shorter for the samples that contained inocula, suggesting that inoculating the biomass had an important, albeit small, effect. The data do not indicate that the presence of high lead concentrations inhibited the microbial activity required for composting. A mean weight loss of $26 \%$ was achieved during these tests. Composted biomass was subjected to a leaching test and was found to leach lead at a slightly higher solution concentration than uncomposted biomass. This would tend to indicate that plants that have been used to phytoextract lead from soil as part of a soil cleanup operation should not be left in the field following phytoremediation.

\section{EM Application}

Field data justifying the widespread use of phytoremediation have only recently begun to be collected; however, success stories involving cleanup of significant problems do exist, and some of the examples are similar to the types of contamination that exist at the various DOE weapons complex sites. It would seem reasonable that phytoremediation could play an increased role in future EM cleanup scenarios. Not only can it be a relatively inexpensive, effective cleanup/polishing tool, phytoremediation is seen by the public in a very favorable light, which may prove to be its biggest asset. This project showed that plants used to remove heavy metals require some sort of postphytoremediation treatment to eliminate the potential for recontamination of the environment. That important fact, coupled with EERC preliminary studies of a few potential processing methods, provides DOE with basic information needed to more widely and appropriately implement phytoremediation at the weapons complex sites. While several phytoremediation topics merit further investigation, optimizing the chelation and extraction process as well as recovering both heavy metals and chelating agents (for successive extractions) from biomass extracts would probably be of the greatest near-term benefit to the EM program. 


\section{Task 26 - Integrated Chemical Reaction Kinetics in Contaminant Transport Model - Phase 1}

\begin{abstract}
Industry Partner
DIAMO, Ltd., Uranium Mining and Processing

Company
\end{abstract}

\section{Duration of Task}

October 1999 - December 1999

Technology Integration Team EERC Task Manager

Project Staff

Jaroslav Solc Robert R. Jensen

\section{Background and Objectives}

Integration of chemical reaction kinetics into contaminant flow and transport models has been identified as a science need under the DOE EM Program. Because of the limitations of currently available models that are not capable of simulating the complex coupled reactive transport, the EERC conducted a search in order to find advanced models that could be applied to solve complex environmental problems addressed by DOE and DOD. Based on an extensive review of published materials, one such model was identified at the DIAMO uranium mining and processing company in the Czech Republic.

The DIAMO program is a 3-D, finite-element flow model coupled with kinetic/equilibrium reactions using the concept of a hybrid element. The model solves a mass balance in the element throughout the 3-D domain in steps by an interelement aqueous solution transfer. The model is structured to permit simulation of saturated and unsaturated contaminant transport at solution mining sites, waste disposal sites, and uranium-processing facilities. Unlike commercially available models, it incorporates coprecipitation and kinetics in 3-D. In addition to the typical geochemical elements, the major radionuclides modeled include $\mathrm{U}, \mathrm{Th}, \mathrm{Ra}, \mathrm{Cs}^{137}, \mathrm{Sr}^{90}, \mathrm{Eu}^{152}, \mathrm{Eu}^{140}$, and $\mathrm{Co}^{60}$.

The EERC plans to perform a preliminary performance evaluation of the current version of the DIAMO model, target the improvement of the model demonstration for presentation to DOE and the national laboratories, and develop a full English version of the model with integrated components specific to EM needs, including cost and risk analysis in interactive scenarios.

\section{Results}

The EERC established contact with the DIAMO modeling group in 1999, visited its site, and conducted a preliminary model evaluation based on model demonstration and presentations given by DIAMO personnel. The DIAMO GWS software package represents a fully 3-D finite element model coupled with reaction kinetics for saturated and unsaturated media. In addition, the EERC and DIAMO agreed on developing and integrating an interactive remediation cost and risk analysis model utilizing in-time increments representing specific cleanup phases.

The EERC found the DIAMO model fully capable of simulating complex environmental problems typical for DOE and DOD sites, including its general application in environmental and mining industries.

The EERC recommended further development and modification of the model's demonstration version, but this additional work, including the full English version of the model and interactive cost and remediation modules, was not funded.

\section{EM Application}

Integration of chemical reaction kinetics into contaminant flow and transport models has been identified as a science need under the DOE EM Program. The DIAMO model is appropriate for addressing site-specific contaminant transport at DOE sites. This model also has the potential for integration of cost and risk analyses in interactive scenarios. 